Florida International University FIU Digital Commons

\title{
Cognitive and noncognitive variables that predict Florida Community College radiography program graduates' success on the registry
}

GregoryJ. Ferenchak

Florida International University

DOI: $10.25148 /$ etd.FI15101363

Follow this and additional works at: https://digitalcommons.fiu.edu/etd

Part of the Higher Education Commons

\section{Recommended Citation}

Ferenchak, Gregory J., "Cognitive and noncognitive variables that predict Florida Community College radiography program graduates' success on the registry" (2009). FIU Electronic Theses and Dissertations. 3292.

https://digitalcommons.fiu.edu/etd/3292 
FLORIDA INTERNATIONAL UNIVERSITY

Miami, Florida

COGNITIVE AND NONCOGNITIVE VARIABLES THAT PREDICT

FLORIDA COMMUNITY COLLEGE RADIOGRAPHY PROGRAM GRADUATES'

SUCCESS ON THE REGISTRY

A dissertation submitted in partial fulfillment of the requirements for the degree of DOCTOR OF EDUCATION

in

HIGHER EDUCATION

by

Gregory J. Ferenchak

2009 
To: Interim Dean Kingsley Banya

College of Education

This dissertation written by Gregory J. Ferenchak, and entitled Cognitive and Noncognitive Variables that Predict Florida Community College Radiography Program Graduates' Success on the Registry, having been approved in respect to style and intellectual content, is referred to you for judgment.

We have read this dissertation and recommend that it be approved.

Kathleen Blais

Victoria Menzies

Martha Pelaez

Janice Sandiford

Kingsley Banya, Major Professor

Date of Defense: February 26, 2009

The dissertation of Gregory J. Ferenchak is approved.

Interim Dean Kingsley Banya College of Education

Dean George Walker University Graduate School

Florida International University, 2009 
() Copyright 2009 by Gregory J. Ferenchak All rights reserved. 


\section{DEDICATION}

To my brothers and sisters for their encouragement, love, and support, and in memory of my parents. 


\section{ACKNOWLEDGMENTS}

I extend my sincere appreciation to my major professor, Dr. Kingsley Banya, for agreeing to lead me through this process. My deepest gratitude is extended to my other dissertation committee members. First and foremost, special thanks are extended to Dr. Janice Sandiford for providing me with countless hours of valuable advice and editorial feedback over the past years and through two dissertation boot camps. Next, I wish to thank Dr. Martha Pelaez for agreeing to serve on my committee despite her busy workload. Lastly, I extend a special thank you to Dr. Kathleen Blais and Dr. Victoria Menzies for joining my committee as the health science content experts.

I wish to thank two of my fellow doctoral classmates for their help and support over the years. I could not have passed the statistics courses without the help of Gregory Singleton. We collaborated on several class projects and became lifelong friends. His encouragement was extended when I needed it most. To Dr. Roberto J. Hernandez, I cannot begin to thank him for all of his advice, help, and encouragement during the many hours we spent on the weekends in our study carrels. 
Since I began my dissertation, my brothers and sisters were always there offering words of encouragement. Special thanks are extended to them for their prayers and understanding when I was not always available.

To my friend James E. Evans, a special thank you from the bottom of my heart. He was always willing to help me in every way possible and provided me with an overabundance of prayers and encouragement to see me through my dissertation to the very end. I could not have had a better friend and colleague.

Finally, I want to acknowledge my supervisor at Broward College, Dr. Barbara J. Bryan, Provost of the North Campus for her constant encouragement, patience, and support as I completed my dissertation. 


\begin{abstract}
OF THE DISSERTATION
COGNITIVE AND NONCOGNITIVE VARIABLES THAT PREDICT FLORIDA COMMUNITY COLLEGE RADIOGRAPHY PROGRAM GRADUATES' SUCCESS ON THE REGISTRY
\end{abstract}

by

Gregory J. Ferenchak

Florida International University, 2009

Miami, Florida

Professor Kingsley Banya, Major Professor

This study examined the predictive merits of selected cognitive and noncognitive variables on the national Registry exam pass rate using 2008 graduates ( $n=175$ ) from community college radiography programs in Florida. The independent variables included two GPAs, final grades in five radiography courses, self-efficacy, and social support. The dependent variable was the first-attempt results on the national Registry exam. The design was a retrospective predictive study that relied on academic data collected from participants using the self-report method and on perceptions of students' success on the national Registry exam collected through a questionnaire developed and piloted in the study. All independent variables except self-efficacy and social support correlated with success on 
the national Registry exam $(p<.01)$ using the Pearson Product-Moment Correlation analysis. The strongest predictor of the national Registry exam success was the end-of-program GPA, $r=.550, p<.001$. The GPAs and scores for self-efficacy and social support were entered into a logistic regression analysis to produce a prediction model. The end-of-program GPA $(p=.015)$ emerged as a significant variable. This model predicted $44 \%$ of the students who failed the national Registry exam and $97.3 \%$ of those who passed, explaining $45.8 \%$ of the variance.

A second model included the final grades for the radiography courses, self efficacy, and social support. Three courses significantly predicted national Registry exam success; Radiographic Exposures, $p<.001$; Radiologic Physics, $p=.014 ;$ and Radiation Safety \& Protection, $p=.044$, explaining $56.8 \%$ of the variance. This model predicted $64 \%$ of the students who failed the national Registry exam and $96 \%$ of those who passed. The findings support the use of in-program data as accurate predictors of success on the national Registry exam. 


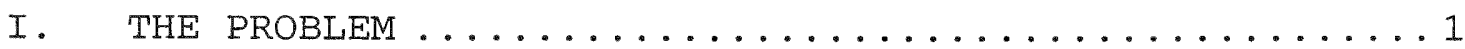

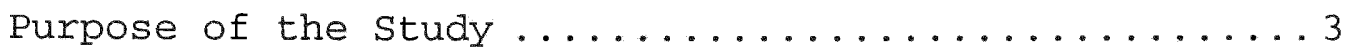

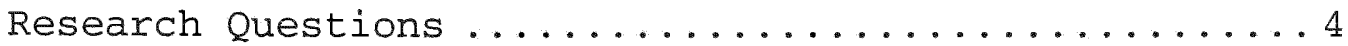

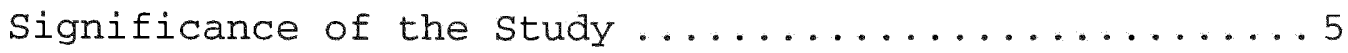

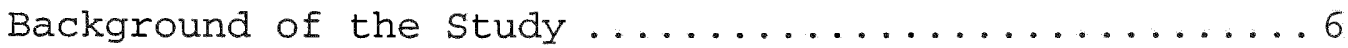

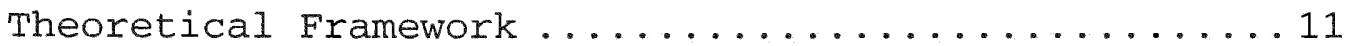

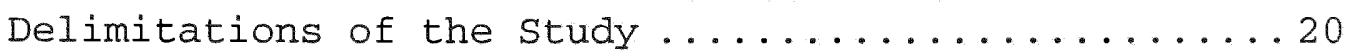

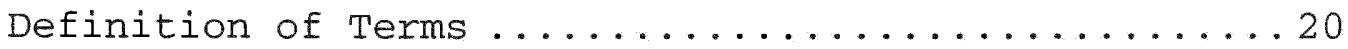
Summary and Overview of Remaining Chapters ........ 22

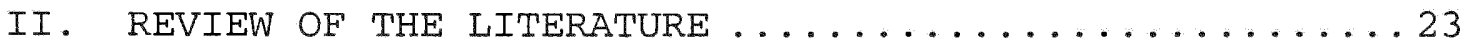

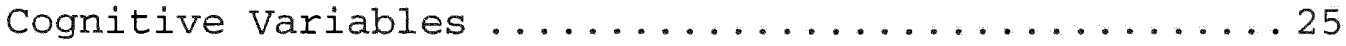

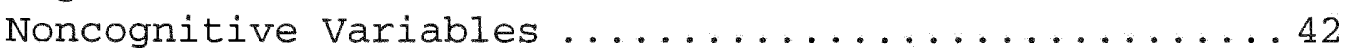

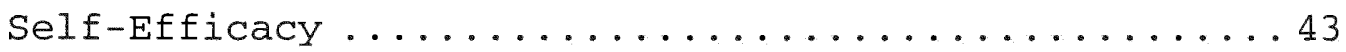

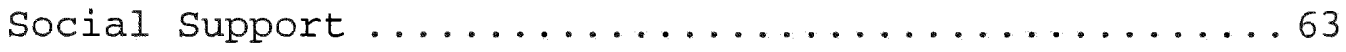

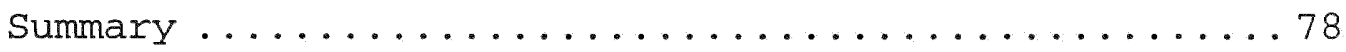

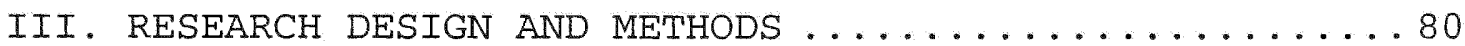

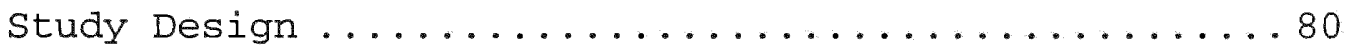

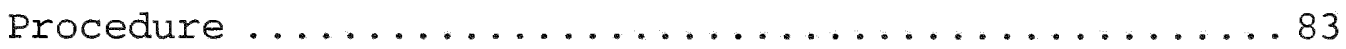

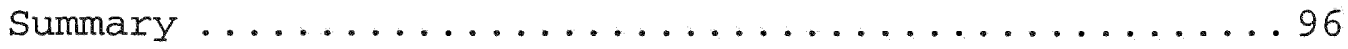

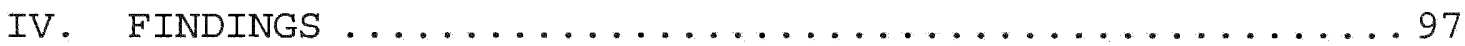

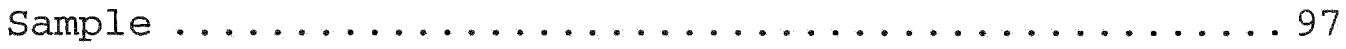

Findings Pertinent to Each Research Question ...... 101

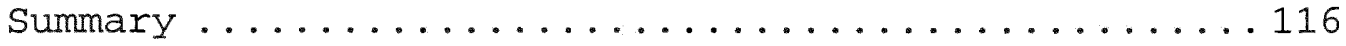

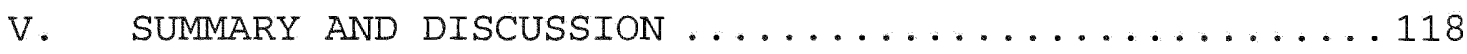

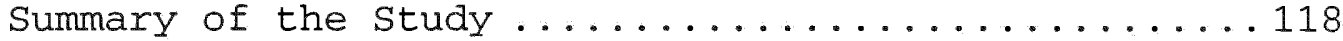

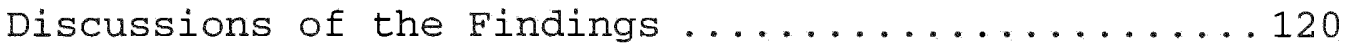

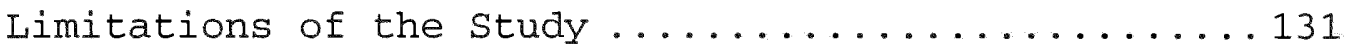

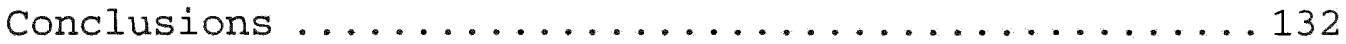

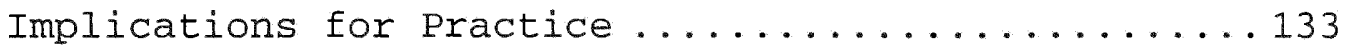
Recommendations for Further Research ............ 134

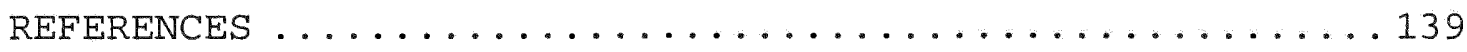

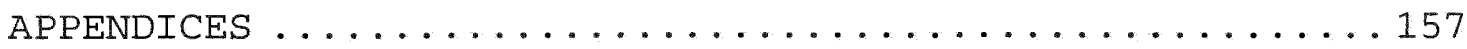

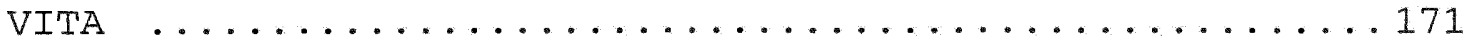




\section{LIST OF TABLES}

TABLE

PAGE

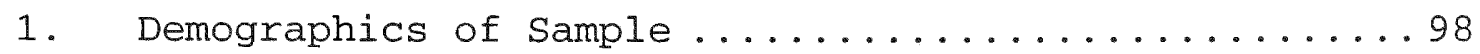

2. Correlations Between Predictor Variables and

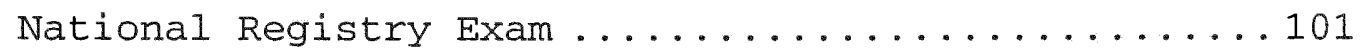

3. Logistic Regression Using the Enter Method .......103

4. Classification Table for End of the Program

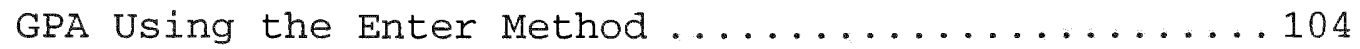

5. Logistic Regression Using the Backward Method ..... 105

6. Classification Table for End of the Program GPA Using the Backward Method ................ 106

7. Radiography Curriculum Course Variables ......... 108

8. Logistic Regression Using the Enter Method for the Selected Courses, Self-Efficacy and

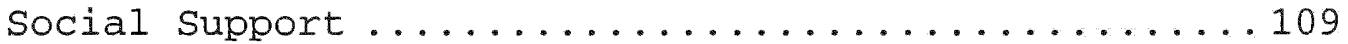

9. Classification Table for RTE Courses 1418,1613,

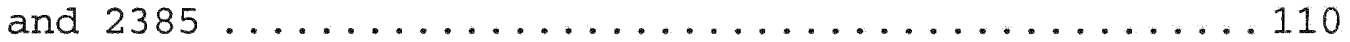

10. Logistic Regression for step 5 Using the

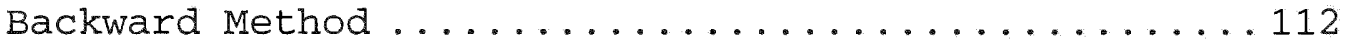

11. Classification Table for step $5 \ldots \ldots \ldots \ldots 112$ 


\section{CHAPTER I}

THE PROBLEM

Even though a student may have successfully graduated from a radiography program, employment as a radiographer is not possible until passing the American Registry of Radiologic Technologists exam (national Registry exam). In 2007, 90.8\% of the Radiography program graduates who sat for the national Registry exam passed on the first attempt but in the state of Florida it was only $82 \%$ (American Registry of Radiologic Technologists, n.d.). To meet the state's projected annual growth rate of $2.5 \%$ for the profession, faculty need some program indicator to predict which students are at-risk for not passing the national Registry exam on the first-attempt so that intervention strategies could be implemented.

Students enter a radiography program with specific cognitive and noncognitive characteristics that may affect how they will perform on the national Registry exam. Most researchers measure these ability or cognitive variables as learning outcomes by using grade point average (GPA) and standardized tests (Oakes, MacLaren, Gorie, \& Finstuen, 1999; Schrader, 1977). The noncognitive characteristics such as self-efficacy and social support affect student 
academic achievement (Astin, 1975; Bandura, 1982; Barrera, Sandler, \& Ramsay, 1981; Weiner, 1974). While the cognitive variables are easy to measure, they may not capture all potential variances, failing therefore to account for all of the variance in predicting success of students in occupational programs.

Self-efficacy and social support are significantly related to academic success (Pintrich \& De Groot, 1990; Sedlacek, 2004). College students in a structured health science program face pressure to progress through the curriculum in sequential order and graduate on time. Academic failure not only prevents them from progressing to the next semester but may affect their self-confidence, self-esteem, and mastery of their future academic competencies. Obligations of the adult community college students require them to have a strong social support network to help them succeed academically. Students with low self-efficacy or a lack of social support will often blame the program instructor for their failure.

Few studies have investigated an inter-correlation matrix as a way to measure both cognitive and noncognitive variables related to learning success. This study developed a three-concept predictor model using ability 
(GPA \& grades) as cognitive variables and self-efficacy and social support as noncognitive variables to address the question: "Is success in school a function of both cognitive and noncognitive variables?"

This chapter includes the purpose, research questions, significance, background, theoretical framework, and delimitations of the study. Definitions of special terms are also presented.

\section{Purpose of the Study}

The purpose of this study was to examine the predictive merits of selected cognitive and noncognitive variables on the national Registry exam pass rate using 2008 graduates from Florida community college radiography programs. The cognitive variables include grade point averages (GPAs) at two progression points and final grades in five program courses. The noncognitive variables include perceived self-efficacy and social support. This study attempted to construct a predictive model for passing the national Registry exam based on these four selected variables. Each variable's ability to predict success (pass) was examined independently of one another. 
This study was conducted to answer the following four research questions:

1. To what degree do the cognitive variables, end of first year GPA and end of program GPA, predict national Registry exam success for graduates from Florida community college radiography programs?

2. To what degree do the cognitive variables, final grades in the program courses RTE 1418 Radiographic Exposures, RTE 1503 Radiographic Procedures I, RTE 1513 Radiographic Procedures II, RTE 1613 Radiologic Physics, and RTE 2385 Radiation Safety \& Protection predict national Registry exam success for graduates from Florida community college radiography programs?

3. To what degree does the noncognitive variable, selfefficacy, predict national Registry exam success for graduates from Florida community college radiography programs?

4. To what degree does the noncognitive variable, social support, predict national Registry exam success for graduates from Florida community college radiography programs? 


\section{Significance of the Study}

While studies have been conducted in some health sciences disciplines to validate and improve curricula, there seems to be a gap in the literature of studies that predict graduation and success on the national Registry exam for community college radiography students. No predictors of academic success have been identified to empower radiography educators to increase the likelihood of success on the national Registry exam. This research attempts to fill the gap in available knowledge by examining the academic achievement of radiography students and, in particular, to identify some of the factors contributing to their achievement or failure.

Program faculty need to identify which students will require supplementary aid during their radiography education prior to the national Registry exam. Using progression points as predictors of success in college has been documented (Hyers \& Zimmerman, 2002; Waterhouse, Bucher, \& Beeman, 1994) as well as the successful use of intervention when students fall below the established benchmark (Frierson, Malone, \& Shelton, 1993). If progression points could be identified within the curriculum, appropriate intervention could reduce the 
number of graduates who fail the national Registry exam on their first-attempt, thus improving program pass rates and increasing the probability of meeting or exceeding the Joint Review Committee on Education in Radiologic Technology (JRCERT) pass-rate benchmark; a 5-year pass rate average on the national Registry exam of $75 \%$ (Stiewing, 2001).

Consistently high failure rates on the national Registry exam may have a negative impact on a program. Poor outcomes could affect a program's accreditation, the number of applicants to the program, the number of graduates entering the workforce, and a program's ability to meet community needs. The results of this study may be used by faculty to help avoid these negative outcomes.

$$
\text { Background of the Study }
$$

In order to improve a radiography program's first-time pass rate on the national Registry exam, factors that can predict success on the exam must be identified. Knowing why students are unsuccessful on the national Registry exam will help faculty guide the unsuccessful graduates preparing to re-test but more importantly, help prevent future graduates from making the same mistakes. Faculty inherently investigate why established educational outcomes 
are generally met, but not by all students in the cohort. Their first instinct is to review students' academic histories in the form of their GPA and/or standardized test scores, which are referred to as cognitive variables. Cognitive Variables

Each year colleges and universities everywhere use the GPA as the basis to select a finite class cohort from an applicant pool. When enrollment is limited, selection criteria that are fair to the majority of applicants must be implemented. Since prediction of future performance is not perfect, admissions is not an exact science. Rarely is there total agreement on the most important criteria for student success.

Academic achievement is one aspect of student performance where there is general consensus. The GPA, which is typically used to measure student academic achievement, is the most widely used and available indicator of student performance in college today. Lamm and McDaniel (2000) found it to be the strongest cognitive predictors of success in nursing baccalaureate students on the National Council Licensure Examination-Practical Nurse. The undergraduate GPA has great significance beyond graduation because it is included in the selection criteria 
for graduate school. In addition, prospective employers may ask for the GPA when considering an applicant for employment.

Young (1993) indicated that the GPA is not a perfect indicator of what a student has learned, but it is often used in educational research for the following reasons: (a) it is a relatively well-defined criterion, (b) it is widely understood, and (c) it is easily and quickly obtainable from college records. He further states, "Due to the lack of criterion measures with these desirable characteristics for other significant aspects of a student's performance in college, validation studies of the admissions process often focus exclusively on the prediction of college grades." (p. 151). For these reasons, GPA has been selected as a cognitive variable for this study.

Astin (2001) also discussed the GPA controversy. Studies of undergraduate grades rarely involved more that one institution. Researchers and educators have argued that predicating GPAs across different colleges simultaneously made little sense because grading systems and academic standards differed greatly. According to Astin (2001), the strongest argument against the use of grades is that they are relative indices and therefore suspect as measures of 
the student's intellectual growth and development. He even argued that grades reflect only how the student is performing relative to other students at a given point in time and do not necessarily indicate what has been learned (Astin, 1974, 1991). But unfortunately there are times when the GPA is the only measure available with which to compare students.

Astin (2001) further indicated that colleges and universities continue to rely heavily on traditional letter grades to assess student achievement, and such grades are still weighted heavily by many graduate and professional schools in their selection procedures. Undergraduate students continue to be dismissed at most colleges for poor grades while high grades continue to be necessary for admission to most graduate and professional schools. Consequently, college grades continue to represent an important index of student achievement.

The cognitive variables, course grades and cumulative GPAs, may be uncontrollable variables due to instructor bias, different grading criteria and grading scales, making comparison challenging. Nevertheless, admission to colleges and universities, as well as programs within those institutions, has been based on GPAs, which are often from 
different academic institutions. Despite the differences in the sources of these GPAs, studies have shown that the GPA accurately predicted success within the programs (Byrd, Garza, \& Nieswiadomy, 1999; Lamm \& McDaniel, 2000; Sandow, Jones, Peek, Courts, \& Watson, 2002). In most occupational programs, the curriculum is standardized by the state or licensing agency so there is a good chance that GPA could be useful as a predictor variable in this study. Noncognitive Variables

There are many noncognitive variables that can enhance or supplement the cognitive variables that affect academic success. DeAngelis (2003) found that an atypical. noncognitive predictor of academic achievement, the Problem Solving Inventory, enhanced the predictive capacity of entering GPA and ACT score, two traditional cognitive measures. In a study by Tracey and Sedlacek (1985) two noncognitive variables that significantly predicted academic success were positive self-concept and realistic self-appraisal.

Self-efficacy and social support are two noncognitive variables that were the focus of this study. Although the construct of self-efficacy (Bandura, 1977) has a relatively brief history beginning in 1977, it has received attention 
in educational research, especially in the area of academic motivation (Pintrich \& Schunk, 1995). Social support affects academic success but it has also been shown to be valuable for the promotion of psychological well-being and individuals' adjustment (Dunkley, Blanstein, Halsail, Williams, \& Winkworth, 2000; Elliott, Herrick, \& Witty, 1992). Social support from family and friends may also assist first-year college students handle their academic stress and transition to the demands of college in more productive and healthier ways (Dwyer \& Cummings, 2001; Shumaker \& Hill, 1991). Finally, social support has been reported to be a useful asset received from family and friends at various times and to varying degrees (Jung, 1989; Kuh, Kinzie, Schuh, \& Whitt, 2005; Procidano \& Heller, 1983). All of these studies support the notion that noncognitive variables can predict academic success in college. Figure 1 illustrates the researcher's conceptual framework of the relationship between the cognitive and noncognitive variables and the dependent variable.

Theoretical Framework

Two constructs that have been found to positively correlate with academic success are the foundational 
support for this study. These frameworks are self-efficacy and social support.

Independent

Variables

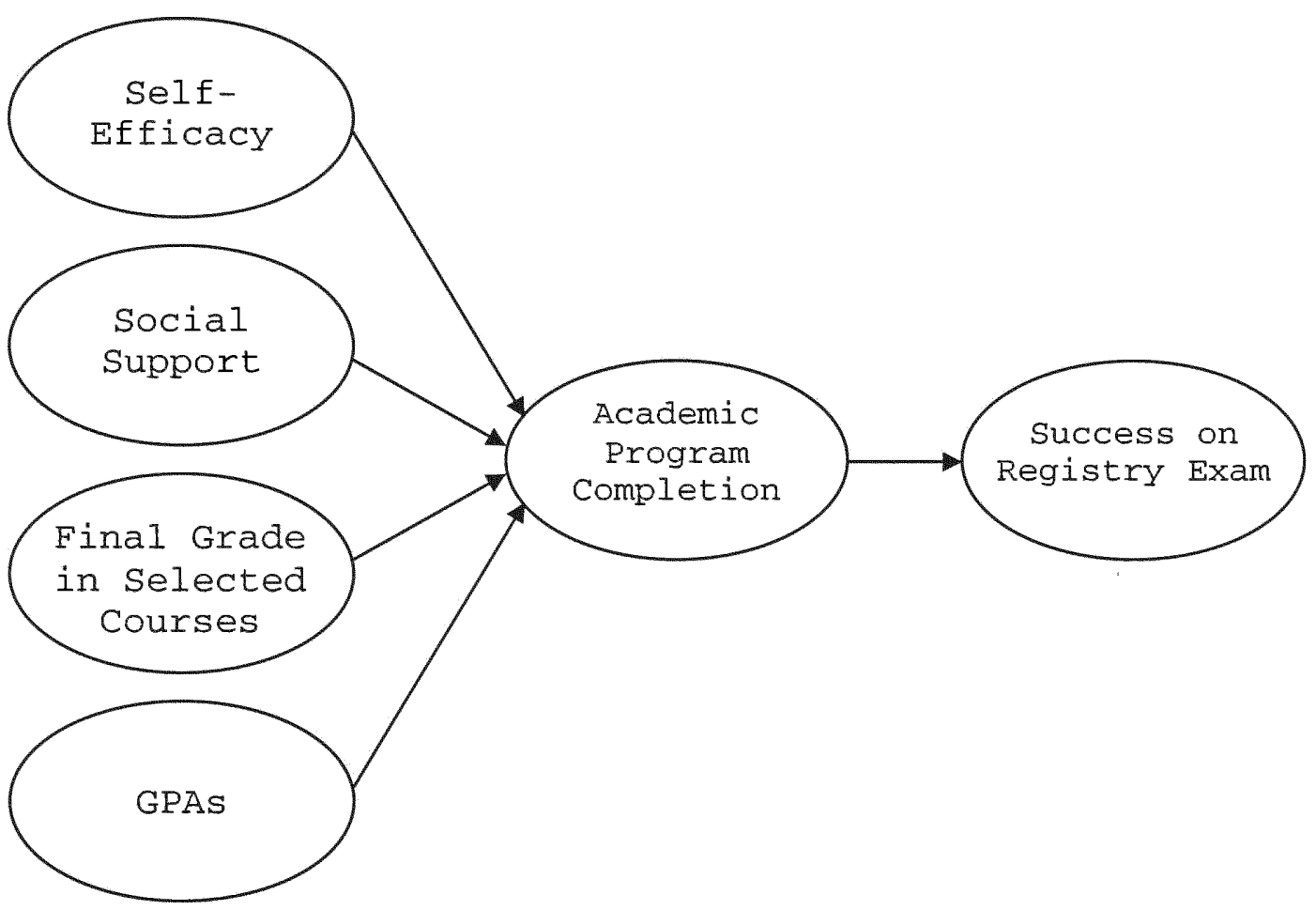

Figure 1. Model for national Registry exam success. Self-Efficacy Framework

The first construct is Bandura's (1982) concept of self-efficacy. According to Schwarzer (1992), perceived self-efficacy reflects an optimistic self-belief that one can perform difficult tasks and facilitates goal setting and persistence, despite barriers. A major objective for health sciences students is to pass the certification or state licensing exam on their first attempt. As students 
progress through the curriculum, they achieve minor objectives by passing courses, thus increasing their selfefficacy. According to Bandura (1982), as students master tasks, their future expectations for mastery of similar tasks are increased (e.g., mastering the national Registry exam) .

Wood and Locke (1987) found that self-efficacy was significantly related to academic performance while other researchers in the area of academic achievement have reported that perceived self-efficacy is one of the more successful predictors of academic achievement (Gore, 2006; Klomegah, 2007). Similar results have been found in mathematics (Schunk \& Hanson, 1985; Schunk, Hanson, \& Cox, 1987). These studies provide a framework for understanding the relationship between self-efficacy and academic performance.

The concept of self-efficacy was introduced by Bandura in the late 1970s, and eventually became one of the key components of his social cognitive theory. It was during the treatment of phobic patients with mastery modeling techniques that he found individual differences in generalization even though all subjects could successfully interact with the target of their fear without adverse 
consequences at the end of therapy. He observed that some subjects developed a strong outcome expectancy that when using proper techniques, would guard them from adverse consequences. This group differed in their perceived capabilities to apply techniques outside the sessions. The individual difference Bandura observed was called selfefficacy, which he measured with task-specific scales. Self-efficacy measures focus on performance capabilities. Since Bandura (1977) defined it as personal judgment of one's capabilities, questionnaire items are task specific, vary in difficulty, and capture degrees of confidence. Finally, self-efficacy judgments refer to future functioning and are assessed before the actual activity occurs. Therefore, self-efficacy judgments play a causal role in academic motivation.

Researchers in the field of self-efficacy and academic achievement propose that there is a relationship between a student's perceived self-efficacy and achievement. Selfefficacy is one of the many methods of approaching academic achievement. This approach does not negate other approaches but it has shown to exert an effect on performance regardless of actual ability. Because self-efficacy theory lies within the general construct of general theory, 
it is equally applicable to classroom, clinical or laboratory settings.

A study by Pajares and Miller (1994) was based on Bandura's hypothesis regarding the predictive and mediational role of self-efficacy in the area of mathematics. The interplay between self-efficacy and selfconcept was also investigated. They posited that selfefficacy mediated the effect of gender and prior experience on self-concept, perceived usefulness, and problem solving. Through the mediational role of self-efficacy, they found that gender and prior experience influenced self-concept, perceived usefulness, and problem solving. Their results supported the hypothesized role of self-efficacy in Bandura's social cognitive theory. Social Support Framework

The second framework used in this study was social support. Research in the field of social support and academic achievement suggests there is a relationship between student perception of social support and achievement. In the literature, social support has focused mostly on the stress buffering aspect of its relation to health. Social support has been important for those in the social sciences but it has also transferred to the 
instructor-student relationship. In this study, social support is constrained to that which is provided by the radiography program instructors to determine their influence on student success on the national Registry exam. Initially examined during the mid 1970s to early 1980s, the concept of social support was used in concrete terms, and referred to an interaction, person or relationship (Veiel \& Baumann 1992). Definitions of social support found in the literature are numerous but there is no universally accepted definition of this construct. Cobb (1976) defined it as information that confirms that an individual is cared for, valued, and "belongs to a network of communication and mutual obligation" (p. 300). Procidano and Heller (1983) defined social support as "...the extent to which an individual believes that his/her needs for support, information, and feedback are fulfilled" (p. 2). Despite the use of different terminology, the definitions all possess common characteristics. According to Rook \& Dooley (1985), all of them imply some type of positive action or helpful behavior provided to a person in need of support. Hupcey (1998) found that the theoretical definitions of social support could be placed into five categories. 
The category relevant to this study is related to the recipient's perceptions of support.

Much of the groundwork for discussion and research of social support was laid by three scholars: Cassel (1974a; 1974b), Caplan (1974), and Cobb (1976). Cassel (1974a) first maintained that social support had a key role in stress-related disorders. Using the term support system, Caplan (1974) included pieces of Cassel's (1974a; 1974b) work into his beliefs of the role that others could possibly play in influencing the course and outcomes of crises and developmental transitions experienced by an individual. Cobb's (1976) view of the importance of social support in relation to stress and well-being was very similar to that of both Cassel (1974a, 1974b) and Caplan (1974). Social support theory is centered on the role of supportive relationships that prevent and reduce the harmful effects of stress and enhance individuals' ability to cope effectively with stress in specific social settings (Jacobi, 1991; Pretty \& McCarthy, 1991).

Tracey and Sedlacek (1984a, 1984b, 1985, 1989)

conducted research in the area of social support in higher education, using the term "strong support person" in place of social support. In his noncognitive assessment in higher 
education research, Sedlacek (2004) found a link between social support and academic success. He found that students who have done well in college usually have someone with strong influence who confers advice, particularly in times of crisis. Furthermore, Sedlacek indicated that traditional students and nontraditional students find their person of strong support from different sources.

In his research on student attrition, Tinto (1993) proposed that colleges are composed of many different communities or subcultures. He believed that student membership in one or more of these communities could increase the probability of persistence. Tinto compared these "supportive communities" to the social support theory. When applied to the collegiate setting, research supports the conclusion that the establishment of supportive personal relationships, whether it be with faculty, peers, or other significant persons, empower students to better deal with the demands of college (Ostrow, Paul, Dark, \& Behrman, 1986). As a result, student academic success is positively influenced.

Astin (2001) also included social support in his study of student perceptions of the college environment. His research on social support was conducted under the term 
"student-oriented faculty". In his 1989 study, Astin concluded that students' perceptions of how studentoriented the faculty was depended much more on students' actual experiences during college rather than on any predisposition they might have had to see faculty in a certain way.

Although found to be important to all students, as far as persistence in college is concerned, having a strong support person is even more important for nontraditional students. Both Nettles (1990) and Johnson (1996) have shown that African American students find it difficult to form relationships with faculty and staff, which Fries-Britt (2000) found to be important. Analogous results were found when mentoring African American graduate researchers (Davidson \& Foster-Johnson, 2002). Fleming (1984) found that the existence of supportive relationships was essential for the persistence and intellectual development of African American students. Having a strong support person has been shown to have a significant correlation among grades, retention, and graduation for African Americans (Tracey \& Sedlacek, 1984a, 1984b, 1989), women (Ancis \& Sedlacek, 1997), and international students (Boyer \& Sedlacek, 1988). 
Delimitations of the study

This study is delimited to the population of 2008 radiography graduates from community college radiography programs in the state of Florida, and who took the national Registry exam by the end of September 2008. Only firstattempt, pass or fail, results on the national Registry exam were used in this study.

\section{Definition of Terms}

Terms that are relevant to this study are defined in this section. Operationalized variables are also presented. End of first year grade point average. The grade point average calculated using all "RTE" prefix courses completed in the first year of the curriculum. The calculated end of first year GPA will be used as an independent variable in the study.

End of program grade point average. The grade point average calculated using all courses included in the radiography curriculum. The calculated end of program GPA will be used as an independent variable in the study. Joint Review Committee on Education in Radiologic Technology (JRCERT). The independent accrediting agency recognized by the United States Department of Education to 
accredit radiography and other programs. Programmatic accreditation by the JRCERT is voluntary.

National Registry exam. A national standardized exam written by The American Registry of Radiologic Technologists (ARRT) taken upon completion of a radiography program that graduates must pass to be granted registry status as a Radiologic Technologist. Passing this exam is required to become employed as a radiographer in all 50 states. The exam is administered via computer format and requires a minimum scaled score of 75 to pass. The dependent variable will be recorded as either pass or fail. Perceived self-efficacy. Beliefs in one's capabilities to organize and execute the course of action required to manage prospective situations (Bandura, 1997, p. 2). The operational definition for the purpose of this study is that self-efficacy reflects an optimistic self-belief that one can perform difficult tasks and facilitates goal setting and persistence despite barriers.

Social support. An exchange of resources "perceived by the provider or the recipient to be intended to enhance the well-being of the recipient" (Shumaker \& Brownell, 1984, p. 13). The operational definition for the purpose of this 
study is that social support refers to the helpful behavior provided to the students by their radiography instructor. Summary and Overview of Remaining Chapters

The radiography curriculum should prepare students for employment as a radiographer. But employment is only possible after passing the national Registry exam. To ensure first-time success on the national Registry exam, faculty must plan learning activities that reinforce the objectives in the curriculum. Courses need to be sequenced appropriately so that the lower level objectives are presented in the initial year and followed by higher level objectives that require critical thinking and problem solving. In order to determine curriculum validity and product (graduate) quality, the programs must be evaluated using external measurement tools such as graduate success rates on the national Registry exam and graduate student perceptions.

A review of relevant literature is provided in the next chapter. Chapter 3 contains the Method section with an overview of the research design, sample, and how the data were analyzed. The results are presented in chapter 4, and chapter 5 includes a summary, conclusions, and recommendations for future research. 


\section{REVIEW OF THE LITERATURE}

This chapter reviews the relevant literature on how the selected variables of GPA, course grades, selfefficacy, and social support predict academic success and success on state licensing or national certification exams. The two theoretical frameworks that serve as the basis of this study, self-efficacy and social support were presented in chapter 1 .

Chapter 2 is organized into two major sections. The first section presents studies that included the cognitive variables of GPAs, course grades and progression points as predictors of academic success. The second section includes the noncognitive variables of self-efficacy and social support as predictors of academic success at various educational levels.

Educators are involved with student outcomes assessment. Determining the amount of knowledge that students develop in educational programs is a critical component of assessment. Administering high stakes tests, such as the ACT, SAT or GRE predicts the ability of students to succeed in educational settings /Campbell \& Dickson, 1996; House, Keely, \& Hurst, 1996; Oakes et al., 
1999; Schrader, 1977). Certification exams such as the law and medical boards, the nursing and education licensure exams are indicators of safe practice and serve as gatekeepers to enter professions. Course completion indicates students' progression toward licensure and practice but cannot be the only indicator of success. What occurs between completion of the educational process and taking the licensure exam is highly complex: a sound curriculum, competent instructors, good study habits, and strong test-taking skills. Much of these are classified as noncognitive indicators that are often not evaluated as they are difficult to isolate. However, noncognitive indicators contribute to student success.

To address the strength of noncognitive indicators as predictors of academic success, this study explored two noncognitive variables, i.e., self-efficacy and social support. Indicators such as self-efficacy and social support have the potential to enhance student efforts as they strive to pass courses and eventually certification exams. Therefore, the purpose of this study was to compare two noncognitive variables, self-efficacy and social support, with cognitive academic indicators to determine how they might contribute to the overall success of 
radiography students to pass the national Registry exam on the first-attempt. Knowing how noncognitive variables interact with measurable cognitive variables can provide educators with insight and perhaps improve program outcomes.

The need to predict success in health science programs or on state licensing examinations has moved researchers to identify cognitive and noncognitive factors that are linked with positive outcomes (Andrews, Johansson, Chinworth, \& Akroyd, 2006; Bauchmoyer, Carr, Clutter, \& Hoberty, 2004; Stark, Feikema, \& Wyngarden, 2002). The current study investigated the predictive merits of selected cognitive and noncognitive variables on the national Registry exam using 2008 graduates of Florida community college radiography programs.

\section{Cognitive Variables}

Cognitive variables have been studied in post secondary and health science education to determine whether or not they can predict academic success. Researchers have used four main categories of independent cognitive variables to predict success on certification examinations; (a) high school grades (Barry, 1984; Mills, Sampel, Pohlman et Becker,1992), (b) college GPA (Dell \& Valine, 1990; Lamm 
\& McDaniel, 2000; McKinney, Small, O’Dell, \& Coonrod, 1988), (c) final course grades (Hill-Besinque, 2000; Hyers \& Zimmerman, 2002), and (d) selected progression point within the curriculum (Beeson \& Kissling, 2001; Horns, O'Sullivan, \& Goodman, 1991; Payne \& Duffey, 1986; Stuenkel, 2002; Yates, 2007). Cognitive Variables: Predictive Studies

Numerous health science programs offered in higher education institutions lead to licensure or certification in the studied discipline. Because graduates' performance on licensure exams is critical to program viability and reputation, nursing literature is rich with reports of prediction studies as far back as the early 1980s (Ashley \& O'Neil1,1991; Dell \& Valine,1990; Jenks, Selekman, Bross, \& Paquet, 1989; Krupa, Quick and Whitley,1988; McKinney, Small, O’Dell \& Coonrod,1988; Mills, Sampel, Pohlman, \& Becker, 1992). These studies are now outdated because of the changes in the curriculum and the method of test administration. Most were conducted using Bachelor of Science degree in nursing (BSN) program students. Most used GPAs and final course grades as variables and multiple regression to examine data. Many used students from only one nursing program, thus limiting generalizability. 
Roye (1997) conducted a retrospective study to investigate the predictive ability of selected admission variables (ACT and SAT scores, and cognate GPA) on the performance of 194 graduates of a Texas community college associate nursing degree program on the NCLEX-RN using three years of data. NCLEX-RN results revealed that $95 \%$ of the graduates passed and ten failed. Since inferential statistics could not be applied due to the low number of students who failed the NCLEX-RN, it was not possible to test the hypotheses, draw conclusions, and make generalizations about the sample population. The results did indicate that the values for all three selected admission variables were all higher for those students who passed the NCLEX-RN. The two delimiting factors of this study were the use of one community college associate nursing degree program and not including noncognitive variables.

Landry (1997) conducted a study to determine how well not only admission and demographic variables could explain and predict variation in graduate performance on NCLEX-RN, but academic and programmatic variables as well. Landry used 360 graduates from one baccalaureate nursing program for the study. Analysis of $t$ - and $z$-tests indicated that 
the two outcome groups (pass and fail groups) differed significantly in terms of ethnicity and gender, as well as the academic variables (ACT Composite score; cumulative, nursing and science GPA's; and number of nursing and support courses repeated). The final logistic regression model indicated that gender, nursing GPA, number of nursing and support courses repeated, and the mean educational level of the clinical nursing faculty were significant $(p<.05$, one-tailed probability) predictors of NCLEX-RN performance. The delimitations of this study were the use of one population to obtain a sample, excluding noncognitive variables and in-program nursing course grades. This study indicated that in-program nursing GPAs can predict success on NCLEX-RN.

Lamm and McDaniel (2000) also identified variables that accurately predicted success on a health science professional licensing exam but used a different curriculum. Their sample consisted of 667 graduates from a practical nursing program who took the NCLEX-PN from 1992 to 1996 . The results indicated that the overall GPA and course grades for Anatomy \& Physiology I and II were significantly correlated with NCLEX-PN success. Overall GPA had the strongest correlation ( $r=0.43, p<.001)$. 
Percoco (2002) conducted a retrospective study to evaluate the influence of selected performance characteristics on successful completion of an associate degree in nursing program and success on the NCLEX-RN. This study excluded admission and major specific course predictor variables. Data collected on 177 students included pharmacology and psychology course grades and GPAs of biology and English courses. The logistic regression indicated that course grades in psychology $(p<0.01)$ and pharmacology $(p>0.05)$, and biology GPA $(p>0.05)$ were predictors of program success. The model accurately predicted program success $77 \%$ of the time. The only predictor of NCLEX-RN success was the pharmacology grade $(p>0.008)$. This model classified those successful on the NCLEX-RN at a rate of $78 \%$. Findings revealed that general education courses did not demonstrate relationships with success on the NCLEX-RN. The delimitations of this study include using only one source, no in-program nursing courses, or any progression points. The findings did indicate that general education courses were not useful in predicting success on the NCLEX-RN, thus the current study did not include final grades in general education courses 
to determine whether or not they could predict success on the national Registry exam.

Considering progression points as possible predictors of success, Stuenkel (2002) investigated the predictive value of various achievement measures on NCLEX-RN success. Using a public university as the setting, a convenience sample $(n=312)$ of student nurses who graduated from 1997 to 2000 and who took the NLCEX-RN for the first time between 1997 and 2001 were used in the study. A number of independent variables, including nursing theory course GPA and cumulative nursing GPA were used in this study. These variables were also measured at different progression points or specific points in the curriculum. The NCLEX-RN result of pass or fail was the dependent variable. This study is relevant because the current study is also based on in-program GPAs and progression points, and the firstattempt pass/fail results on an external achievement measure.

Stuenkel (2002) indicated that the best predictive value was the progression point at the end of the sixth semester. Adding the Maternal-Child Health theory course to the entrance criteria resulted in $81 \%$ of the cases being classified correctly. Stuenkel (2002) used a convenience 
sample $(n=312)$, a single setting, and test scores that are not applicable to radiography for analysis, therefore the results were limited to the population and profession from which the sample was selected. The study indicated that progression points are significant predictors for determining success on the NCLEX-RN which the current study included as a variable.

Collins (2002) conducted an ex-post facto study that included pre- and in-program predictor variables. Grades in pre-program science courses, pre-program cumulative GPA, and grades in selected nursing theory courses were included in this study to determine whether or not these variables could predict pass/fail performance on the NCLEX-RN for graduates of an Associate Degree Nursing program. The study was conducted in a community college with a sample of 159 program graduates. The strongest variable to correlate with performance on the NCLEX-RN was the GPA for the three selected nursing theory courses. The final grade for the Drug Therapy course was the overall strongest predictor $(p<.001)$. Results of the Collins' (2002) study are important because they indicated that nursing theory courses could be used to predict pass or fail on the NCLEXRN. Limitations of this study were the use of one setting 
for the study, students from one health science program, and no noncognitive variables.

In addition to using pre-admission and in-program variables, a study by Yates (2007) included 298 graduates of an associate degree nursing program in the southeastern United States to investigate variables associated with learning, and performance as measured by the NCLEX-RN, to validate the predictive value of the Assessment Technologies Institute Achievement Exit Exam to predict performance on the NCLEX-RN. The Yates (2007) study followed a predictive, correlational design, relying on retrospective data. Point biserial correlations and chisquare analyses were used to investigate relationships between 19 selected predictor variables and the NCLEX-RN dichotomous criterion variable. The results of the correlation and chi square analyses indicated that students who passed the exam started and completed the nursing program with a higher GPA than those who failed the exam. Using logistic regression, one model demonstrated that student performance on the NCLEX-RN could be predicted by one pre-admission measure and a program measure. The following model developed by Yates accurately predicted $94 \%$ of the student's successful performance on the NCLEX-RN: 
NCLEX-RN success $=f($ Nurse Entrance Test and advanced medicalsurgical nursing course grade achieved). This study is delimited by the use of one setting and no noncognitive variables. The study by Yates (2007) did indicate that an in-program course could accurately predict success on the NCLEX-RN and that GPA does influence NCLEX-RN performance. Cognitive and Non-cognitive Variables: Prediction Studies In the 1990 s researchers began to include non-academic variables into their prediction models, especially in the field of nursing. Dell and Valine (1990) conducted study to explain the differences in NCLEX-RN scores with specific cognitive and noncognitive factors for baccalaureate nurse graduates. Their results indicated that collegiate GPA, SAT/ACT scores, self-esteem, and age accounted for $64 \%$ of the variance of the NCLEX-RN scores. Furthermore, GPA was one of the best predictors of success on the NCLEX-RN and the collegiate GPA accounted for the majority of the variance in NCLEX-RN scores. Poorman and Martin (1991) also investigated the role of academic and nonacademic variables in relation to passing the NCLEX. They found that noncognitive factors could be better predictors of NCLEX success than academic variables. 
During this time progression points within the curriculum were also studied by researchers to provide additional knowledge on the subject (Fowles, 1992; Heupel, 1994; Horns et al., 1991; Jenks et a1., 1989; Mills, Becker, Sampel, \& Pohlman, 1992; Payne \& Duffey, 1986; Waterhouse, Bucher \& Beeman, 1994). Again, these researchers focused their research on BSN students, used small sample sizes or only one program. They did however set examples of the many ways prediction research in nursing may be conducted.

Additional prediction studies were later conducted as testing methods changed. Beeman and Waterhouse (2001) explored the potential to predict success on the NCLEX-RN computerized exam version. Beeman and Waterhouse's (2001) study is relevant to the current study because the national Registry exam for radiography is also computerized and previously mentioned studies using radiography programs as the setting did not include the computerized version of the national Registry exam. They used a convenience sample of 538 graduates from one baccalaureate nursing program for their study.

The purpose of the Beeman and Waterhouse (2001) study was to identify which of 21 variables can be significant 
predictors of success on a computerized (CAT) NCLEX-RN. Some of the predictor variables used in the study included final grades for specific curriculum courses, the number of $\mathrm{C}+$ or lower grades received in nursing didactic courses, number of $\mathrm{B}$ or lower grades received in clinical courses, and GPAs for the end of the sophomore year and after the first senior semester. Results indicated that the number of $\mathrm{C}+$ or lower grades received in nursing didactic courses showed the highest correlation with NCLEX-RN success $(r=-0.394, p<.0001)$, followed by grades in two nursing courses $(p<.0001)$. Grades in the introductory nursing course and pathophysiology course were highly correlated with CAT NCLEX-RN success. More than $94 \%$ of the students who passed the CAT NCLEX-RN were classified correctly by the graduation discriminate analysis and more than $92 \%$ of the students who failed were classified correctly.

Beeman and Waterhouse (2001) concluded that success on the CAT NCLEX-RN can be predicted with at least $92 \%$ and $94 \%$ accuracy for failing and passing candidates respectively. Those who passed earned statistically higher grades in all didactic nursing courses, had significantly higher GPAs, and had a significantly lower number of low theory and clinical grades than those who failed the CAT NCLEX-RN. All 
graduates from the study by Beeman and waterhouse (2001) were from one baccalaureate nursing program, thus limiting the findings, i.e., results could not be generalized to graduates to all baccalaureate nursing programs.

Beeson and Kissling (2001) also conducted a retrospective study to predict success for baccalaureate graduates on the NCLEX-RN but expanded their variables to include pre-program courses. Their sample $(n=505)$ consisted of graduates from one program between 1993 and 1998. Independent variables included, performances on selected prenursing courses, on sophomore, junior, and senior nursing courses, and on cumulative GPAs at graduation. GPAs for nursing courses each year, cumulative nursing GPAs, and cumulative biology GPAs were also considered in building the model.

Study results indicated that students who passed the NCLEX-RN on the first attempt had significantly higher GPAs $(p<.001)$, and made fewer grades of $C$ or below than students who failed (Beeson \& Kissling, 2001). The logistic regression analyses indicated that the most significant predictor of success in this study was the number of Cs, Ds, and Fs in nursing courses students earned through the junior year $\left(x^{2}=108.42, d f=3, p<.0001\right)$ and that 
students who had grades of $B$ or higher had an NCLEX-RN pass rate of $97 \%$. The results also indicated that higher overall GPAs were found to predict NCLEX-RN success. The study by Beeson and Kissling (2001) was limited to one setting for sample selection and different types of interventions were not used as variables to predict NCLEX-RN success.

Sayles, Shelton, and Powell (2003) also studied predictors of success in nursing education but their sample was drawn from the spring 2001 graduating class $(N=83)$ of an associate degree nursing program who took the NCLEX-RN and were successful on the first-attempt. The sample for this study consisted of the 68 graduates who took and passed the NCLEX-RN on the first-attempt.

Sayles et al. (2003) used ACT, GED, GPA, and final grades in nursing courses as the independent variables in the study and pass/fail NCLEX-RN results as the dependent variable. GPA for courses toward the nursing degree were reported as statistically significant $(r=0.285$, $p=0.02$ ). Salyes et al. (2003) corroborated earlier findings, noting once again that GPA for courses toward the nursing degree remained statistically significant $(t=-2.393, p=0.02)$. The researchers reported that as 
GPA towards the nursing degree improved, so did the likelihood of passing NCLEX-RN (Sayles et al., 2003).

One predictive study outside the field of nursing was found in the literature. Hill-Besinque (2000) conducted a study to determine performance predictors for the California State Board (CSB) Examination in Pharmacy. An independent variable in the study was final grades in pharmacy courses while success was defined as passing the CSB examination on the first attempt. The results indicated that the academic performance in pharmacy school was a strong predictor of the passing efficiency in the CSB Examination. In the Hill-Besinque (2000) study, the sample was very small $(n=33)$ and from one setting and one cohort, thereby delimiting the results. Hill-Besinque's (2000) study is relevant to the current study because the method of self-reporting will also be used. Also, the current study will include participants from multiple settings as well as from a different health profession so the results may or may not conflict with Hill-Besinque's (2000) results.

Evaluation of Progression Points in Radiography Studies A review of the literature related to progression points in radiography produced limited results. In one of 
two predictive studies, Ballinger (1976) sought to identify predictors that were most closely related to the overall Registry exam score and that of the radiographic technique section of the same exam. The setting for this study was a two-year certificate program in radiologic technology sponsored by The Ohio State University Hospitals which admittedly was highly selective in their admissions process. The sample included students $(N=112)$ who graduated from the program between 1963 and 1973. Using stepwise multiple regression, Ballinger (1976) found the strongest predictor of success on the national Registry exam was high school graduating percentile $(r=0.451)$. The data collected in this study were based on the former national Registry exam paper-and-pencil format and older test bank of questions, but current testing conditions differ from the proposed study, specifically in testing format, options when to take the exam, and test bank items. However, Ballinger (1976) established a knowledge base of variables that could predict success on the national Registry exam. Through this study, the researcher developed a regression formula using the high school graduating percentile and the ACT English score for use in predicting the Registry scaled score with statistical significance: 
$R_{p}=0.0919$ (high school percentile) $+0.4251\left(\mathrm{ACT}_{\mathrm{e}}\right)+$

70.6230. The validity of this formula has yet to be proven to predict Registry examination success using a sample from a two-year degree granting college.

The second prediction study was conducted by Barry (1984), who sought to identify which variable or set of variables could best predict success on the national Registry exam. Graduates $(N=83)$ from one community college radiography program who took the national Registry exam during the years, 1973 to 1981 were used in this study. Age, high school GPA, and the scores for the different sections of the ACT were used as predictors of success on the national Registry exam. Results indicated that the largest correlation between the dependent and independent variables was high school GPA ( $r=0.56$, $p<.01)$. In the stepwise forward inclusion multiple regression, the largest correlation was high school GPA (F- ratio of $37.3, p<.01)$. High school GPA accounted for $31.5 \%$ of the total variance in study findings. Although it is data within the field of radiography, the limitations of the study by Barry (1984) bar generalization to all radiography programs. For example, sample size was small; data was collected from a single community college 
radiography program; evaluation of in-program progression points or radiography course grades was absent; and use of raw scores on national Registry exam rather than the pass/fail option. Another limitation of the Barry study was that it did not include noncognitive variables. Despite these limitations, findings of the study provided preliminary data within the field. Summary of Cognitive Variables

The use of cognitive variables such as GPAs, course grades, and progression points as predictors of success in college as well as on professional license or certification examinations has been documented. The literature to predict academic success is numerous but inclusive. Small sample sizes (Ballinger, 1976; Barry, 1984), limited settings (Ballinger, 1976; Barry, 1984; Dell \& Valine, 1990; McKinney et al., 1988), unique admissions selection criteria (Ballinger, 1976; Barry, 1984; Hill-Besinque, 2000; Mills, Sampel, Pohlman, \& Becker, 1992), and different curricula (Poorman \& Martin, 1991) make it difficult to generalize the results beyond the original study. The findings can be useful to a limited extent. Data on predicting academic success of a specific gender or minority group (Landry, 1997; Poorman \& Martin, 
1991), using specific admissions criteria (Beeson \& Kissling, 2001; Sayles et al., 2003), and assessment points (Horns et al., 1991; Jenks et al., 1989; Stuenkel, 2002) are plentiful for most levels of higher education. The one area where minimal research has been found is in radiography, where only two outdated studies (Ballinger, 1976; Barry, 1984) were found to be reported in the literature. The need for data on predicting success of community college radiography graduates on the computer format of the national Registry exam is needed to assist faculty in helping students to adequately prepare for this exam.

\section{Noncognitive Variables}

Interest in noncognitive variables became popular in the 1980s because it provided institutions an alternate method of predicting student performance in college (House, 1995a, 1995b; Kanoy, Wester, \& Lata, 1989). Researchers argued that traditional methods, i.e., standardized tests (ACT and SAT), were not valid predictors for all students, especially those in the minority groups (Arbona \& Novy, 1990; Kanoy, et al., 1989: Sedlacek, 2004). Noncognitive variables found to be useful predictors of academic performance were self-efficacy (Stewart, 1990) and social 
support, defined as having a strong support person in one's life (Sedlacek, 2004).

\section{Self-Efficacy}

The construct of self-efficacy has a relatively brief history that began in 1977, but self-efficacy beliefs have received much attention in educational research, especially in the area of academic motivation (Pintrich \& Schunk, 1995). Researchers have correlated self-efficacy to achievement, persistence, and tenacity in educational settings (Bandura, 1986; Schunk, 1981; Zimmerman, 1989). There is evidence that self-efficacy can improve performance in specific cognitive areas.

Completing a meta-analysis of research in educational settings, Multon, Brown, and Lent (1991) found that selfefficacy was related to academic performance and persistence. Analyzing a total of 39 studies with 41 different subject samples, Multon et al. (1991) found that 19 different measures of academic performance were used among the various studies that could be categorized into three groups: standardized tests, classroom-related measures, and basic skill tasks. The unbiased effect size estimate between self-efficacy and academic performance was .38 which differed significantly from zero, based on its 
95\% confidence interval and associated significance test $(z=28.22, p<.001)$. The overall effect size between self-efficacy and persistence (.34) was significant, based on its 95\% confidence interval and associated significance test $(z=11.75, p<.001)$. This investigation by Multon and her colleagues provides support for the relationships of self-efficacy beliefs to academic performance and persistence. The effect size estimates in both metaanalyses implies that across various criterion measures, designs, and samples, self-efficacy beliefs account for about $14 \%$ of the variance in students' academic performance and nearly $12 \%$ of the variance in their persistence.

In a more recent meta-analysis, Robbins, Lauver, Davis, Langley and Carlstrom (2004) examined the relationship between psychosocial and study skills factors and college outcomes in 109 studies. Academic self-efficacy was one of nine different constructs included in the study and performance (GPA) was one of the two college outcomes. The best predictor for GPA in this study was academic selfefficacy ( $p=.496)$, with the estimated operational validity of .378 . Results indicated that out of the ten predictor categories found in all of these studies, academic self-efficacy proved to be the best predictor of 
college outcome. Although these findings are important, there were limitations related to the study findings. For example, the studies ranged across differing methodological empirics, those of education and those of psychology. Empirical studies were limited to atheoretical constructs, single-item survey measurement, and scale construction involving the modification of one or more established measures under a broad theoretical framework. Finally, the presentation of measures did not include an explanation of psychometric properties (Robbins et al., 2004). Self-Efficacy, Persistence and Grade Prediction Solberg and Villareal (1997) found a positive relationship between academic and social measures of selfefficacy with college persistence in a study of Hispanic students $(N=164)$. The study objective was to explore the role of self-efficacy, social support and stress on the personal adjustment of Hispanic undergraduate students from a large west coast university. Self-efficacy and social support were also used to assess retention rates. Findings indicated that the combination of the three predictors tested accounted for a total of $46 \%$ of the variance, with social support and self-efficacy each accounting for $35 \%$ of the variance. Students who perceived social support to be 
available were found to have less distress ratings than students who perceived less social support. Solberg and Villareal (1997) concluded that self-efficacy expectations may be an important predictor of college persistence. One limitation of this study was that social support was not defined, therefore it was unclear who participants considered to be a support person. Study findings, however, provided data that indicated that self-efficacy and social support can predict college outcomes, especially for minority students.

The construct of self-efficacy has been studied to determine its predictive role in specific college courses. Wilhite (1990) examined the relationship between selfefficacy and achievement in a college introductory psychology course. The subjects $(N=184)$ were drawn from six different sections of the course taught by five different instructors. The results indicated that selfefficacy accounted for a significant share of achievement variance. Furthermore, the more positive the students' self-efficacy of academic ability, the better students performed in the course. Limitations of Wilhite's (1990) study included using only one internal measure of academic achievement, one setting for the study, a sample that was 
required to participate in the study, and one course subject area. The study did include different faculty teaching the same content yet using different delivery methods and course requirements to calculate a final grade. House, Keely, and Hurst (1996) also examined the relationship between self-efficacy and achievement in a college introductory psychology course but they used new freshman students $(N=335)$ from two different universities as the study sample. During orientation held prior to the start of the first semester, participants completed a survey to measure their attitudes and achievement expectancies. Results indicated that students' initial attitudes were significant predictors of their succeeding achievement in a general education course (House et al., 1996). For the entire sample, the cognitive variable, i.e., ACT score, was the single significant predictor for whether students earned a satisfactory grade in the selected course. A study limitation was the use of only one achievement outcome, specifically, grade performance. The strengths of House et al.'s 1996 study are twofold: (a) it is generalizable as it included students from two different universities and (b) this study replicated a previous study by House et al., (1993). The majority of the 
other studies reviewed included students from only one institution. Secondly, because the same sets of variables were measured in both studies, the methodology allows for a direct comparison of the results. The merits of the House et al. (1996) study warrant replication to include more than two settings, more than one course grade as an achievement outcome, and students from other academic areas, such as health sciences. Replication of the study using students who must pass a standardized licensure or certification exam should be considered as well.

Pajares and Miller (1994) explored the predictive role of self-efficacy in a math course using voluntary participants $(N=350)$ from a large public university. After students completed four instruments to measure their self-efficacy, they were asked to solve math problems to collect the necessary data for the study. The path coefficient from the math self-efficacy independent variable was significant $(\beta=.545, t=10.87, p<.0001)$. The limitations of this study were the use of only one setting, the sample selection from one college within the university, the problems selected for the study, and the use of only one course. 
House and Prion (1998) investigated the predictive relationship of self-efficacy, academic background and student achievement in a required freshmen English Composition course. New freshman students $(N=257)$ from one college were selected as the study sample. During the new student orientation program that was held prior to the start of the semester, participants completed a survey to measure their attitudes and achievement expectancies. Study results indicated that students who had higher preliminary self-efficacy ratings earned higher grades in their first English course. Results also indicated a significant negative correlation between students' expectations of failing college courses and their English course grades. Study limitations that restrict its generalizability include a sample that was selected from only one institution and the use of only one type of achievement outcome, specifically, grade performance from one course.

House (2001) found that for health science students, self-beliefs and academic background were significantly related to achievement in their subsequent Biological Science courses. There were significant correlations between students' self-rating of their overall academic and mathematical abilities with their grade performance in 
science courses completed later in the curriculum. The limitations of this study include using students from only one institution and using only science courses.

The purpose of Dentlinger's (2003) study was to determine the relationship between measures of prior academic achievement, self-efficacy, and success in a first semester associate degree nursing course. Participants $(N=250)$ in this study were selected from all students registered in the first semester nursing course in nursing programs at all community colleges in Oklahoma. Selfefficacy was measured in this study using Jeffrey's (1998) Self-Efficacy Tool, while prior academic achievement measurements included college GPA. The researcher defined success as passing the first semester nursing course and progressing to the next semester. The results of Dentlinger's (2003) study indicated that self-efficacy had a significant relationship with success, but accounted for only $3.4 \%$ of the variance. Dentlinger's (2003) study was limited by its use of data from only one semester course, including only one noncognitive variable, and not using an external outcome variable, such as a licensure or certification exam. Dentlinger's (2003) study is relevant to the current study because it included cognitive and 
noncognitive variables, a setting of all community colleges in a statewide system, a population from a health science program, and a large sample size.

Exploring the potential association between

motivational factors and college grades, Lynch (2006) used responses to the Motivational Strategies for Learning Questionnaire as the independent variable. A private university was used as the setting for the study and the sample included 501 undergraduates. The results of a stepwise multiple regression analysis indicated that effort, self-efficacy, and external goal orientation yielded significant results $(R=41, F 3,418=27.851$, $p=.00$ ) in predicting course grades. Upper level students' grades were predicted by effort and self-efficacy while those of freshmen were predicted by self-efficacy and extrinsic goal orientation scores predicted. The limitations of Lynch's (2006) study included its one institutional setting, the use of a convenience sample, using course grades from only one semester, and the use of a dependent variable that was not a standardized test. The findings from this study are important because results indicated that self-efficacy was a powerful predictor of student success. 
Self-Efficacy and Academic Performance

It has been found that self-efficacy can penetrate the motivational and behavioral components of academic and social integration and persistence. Lent, Brown, and Larkin (1984) found that self-efficacy was a predictor of both academic performance and persistence, especially for underprepared students. They examined the relationship between self-efficacy beliefs and academic success and persistence among students considering careers in science or engineering. Undergraduate students $(N=42)$ completed several indices of self-efficacy at predetermined progression points in the academic year with data retrieved from the university records. The researchers found that high-level subjects persisted for all quarters included in the study and achieved higher grades, while only 58\% of the low-level group persisted. These study results are noteworthy because in this case, self-efficacy predicted a highly complex set of academic behaviors. Also, efficacy expectations were assessed in relation to specific occupational titles rather than to specific hierarchically structured career-oriented behaviors. As outlined by Lent et al., (1984) a limitation of the study was that the sample did not make the results generalizable to students 
not enrolled in the selected courses. Another limitation was that no standardized examination was used to assess the relationship among self-efficacy, academic aptitude, and academic performance self-efficacy.

House (1993) investigated the predictive relationship between students' achievement expectancies and their subsequent grade performance at three different progression points after initially measuring their attitudes. The study sample included 2,480 new freshman students at one university who entered in the same semester. Prior to the start of the semester, students completed a survey that included nine items to measure their expectancies for subsequent academic performance. Cumulative GPAs at three different progression points were the dependent measures. House (1993) reported that students' achievement expectancies were significant predictors of their subsequent academic performance, predicting students' cumulative GPAs at all three progression points. These findings are important because they indicated that noncognitive variables may be used to predict academic performance at different progression points of the students' academic career. Limitations of the study did not make it generalizable to all populations because only one 
institution was used for the setting and the study failed to consider the effects of students' prior academic achievement. Since House (1993) did not specify the students' major, the results cannot be extended to include health sciences students. Lastly, the outcome measure did not include an external licensure/certification examination to measure with which to compare students' attitudes. It may be informative to replicate the study with students enrolled in health sciences programs and more specifically, radiography.

Wolters, Yu, and Pintrich (1996) studied the relationship of self-efficacy and academic performance in a correlational study using 434 junior high school students who were enrolled in English, mathematics, and social studies classes. To measure classroom academic performance, grades from the three subject areas for the two semesters were collected from school records. Study results indicated that $35 \%$ of the variance was explained for social studies, while for English, 33\% of the variance was explained; and for math, 23\% of the variance was explained. The single best predictor of self-efficacy, with standardized coefficients ranging from .34 in math to .41 in English, was a learning goal orientation. In the results of the 
second semester of this study, a significant portion of the students' self-efficacy for academic tasks was explained in mathematics, social studies, and English. This study is important because it indicated that adopting a learning goal orientation and a relative ability goal orientation can result in a positive pattern of self-efficacy. The results were also replicated across three different academic subject areas. These study results were limited to the population and setting from which the sample was selected, and the courses selected.

Chemers, Hu, and Garcia (2001) also examined the effects of academic self-efficacy on students' academic performance. Participants who were first-year students from one university $(N=373)$ completed questionnaires at two different progression points in their first academic year at the university. The results indicated a significant and substantial direct effect of self-efficacy on academic performance (standardized coefficient $=.34, p<.001$ ) which indicated that students with a high self-efficacy perception earned better grades. There was a significant mediated effect of self-efficacy on academic expectations (standardized coefficient $=.08, p<.001)$ and academic performance (standardized coefficient $=.08, p<.01$ ), 
which indicated that efficacious students had greater academic expectations which ultimately led to better academic performance. Chemers et al.'s (2001) results are noteworthy because they demonstrated persuasive support for the role of self-efficacy in the success of first-year college students. The potential generalizability of the findings is limited by the setting and the measures selected for the study.

Klomegah (2007) conducted a study to determine which variables were better predictors of academic performance of university students. The study sample consisted of 103 undergraduate students from one university who were enrolled in at least one sociology course. Final grades in the sociology course were used to assess student performance. There was a moderately strong positive correlation between self-efficacy and course grade ( $r=.32, N=97, p<.001)$ in the study. High school GPA had the strongest beta weight $(.502, p=.000)$ which indicated that it made the strongest contribution to explain academic performance. The self-efficacy beta coefficient was $.37(p=.01)$, making it the second strongest contributor to explain the dependent variable of academic performance. Klomegah (2007) found that self- 
efficacy had the strongest predictive power of the four variables in the goal-efficacy model, explaining $37 \%$ of the variance in academic performance. The importance of this study is that intrinsic and extrinsic correlates of academic performance should be integrated into future studies. Study limitations included use of only one setting, and selection of a sample from courses in the sociology domain.

Self-Efficacy and Academic Achievement

Self-efficacy was found to have a positive outcome on student academic achievement. Studies have included students from all levels of education and different populations. Jeffreys (1998) conducted a study to determine the relation of self-efficacy and other variables on academic achievement and retention. Students completed researcher developed measures of self-efficacy and student perceptions concerning academic and environmental variables. Study results indicated a moderate amount of variance $(R=.38, p=.01)$ in predicting academic achievement from the combined effect of self-efficacy and the academic and environmental variables. However the sample used by Jeffreys was very small $(n=97)$ and was 
obtained from a unique setting, therefore the results cannot be generalized to other populations.

The Pajares (2001) study showed that self-efficacy beliefs played a significant role in student achievement in the middle schools. The results confirmed the importance of positive self-efficacy beliefs in influencing predictive behavior among students in both the academic and general well-being domains. Pajares' results were limited to the sample (12-13 year old students), setting (public middle school), and the correlational analysis conducted in the study. The researchers encouraged further research to include samples from other populations and academic levels. Alfassi (2003) used high school students $(N=52)$ to compare two instructional practices in two different schools to determine the role of self-efficacy in student achievement. An experimental group of 37 students enrolled in an alternative high school were selected to participate in the study. The control group was comprised of 15 students that used conventional remedial instruction and curricula. Achievement tests, a standardized reading test, a measure of self-efficacy (Academic Self-Efficacy Scale) 
and a motivation scale (Intrinsic versus Extrinsic Orientation Scale) were administered to all students towards the end of the school year.

The results of the MANOVA to test self-efficacy revealed significant differences between the two study groups $F(2,47)=37.99, p<.001$ (Alfassi, 2003). The experimental group (Language Arts $M=4.24$ and Math $M=4.29$ ) differed significantly from the control group (Language Arts $M=3.20$ and Math $M=2.91$ ) and obtained higher mean scores on both measures of self-efficacy. These results indicated that a structured academic program yields significantly higher achievement and self-efficacy scores, and a higher internal motivational orientation. This study is noteworthy because the results indicated that selfefficacy positively affected achievement in school. But as with other studies, these findings were limited to this sample and setting. Generalizability was not possible due to the unique school setting.

Gore (2006) conducted a study using 629 first-year college students from a public university to evaluate the value of using measures of academic self-efficacy to predict college academic success. Cumulative GPA and enrollment were used in the study as the dependent 
variables. The ACT composite score was a significant predictor of GPA for the first 3 semesters of college $(\beta=.235, .240, .267, p<.05)$, accounting for between $6 \%$ and $7 \%$ of the variance. College self-efficacy was also found to be a significant predictor of GPA in every analysis. Self-efficacy accounted for an additional $10 \%$ of the variance in first and second semester GPAs, and an additional $4 \%$ of the variance in the third semester GPA. Results indicated that course self-efficacy was the most consistent predictor of GPA out of the three measures used in the study. The limitations of the study were the use of one setting, sampling from only one course, and surveying the participants in the first semester. Gore's study was important because the results indicated that academic selfefficacy can predict college academic success. Also, the findings indicated that self-efficacy was best measured at the end of the first year.

House (2000) conducted a study using undergraduate students who were health science majors $(n=146)$ to assess the efficacy of self-belief variables and academic background as predictors of academic achievement. In the stepwise multiple regression analysis of cumulative GPA using self-belief variables as the predictors, self-rating 
of mathematical ability and self-rating of overall academic ability significantly entered the equation first and second respectively, and explained a significant proportion of the variance. Self-belief variables explained $19.8 \%$ of the variance in students' cumulative first year GPA. House's (2000) study is important because it documented that selfefficacy, a noncognitive variable, can predict academic success of health science students, which is one of the few studies on self-efficacy to include this population. The limitations of this study included the use of students from one institution and only one GPA progression point. Summary of the Literature on Self-Efficacy Self-efficacy has been shown to be correlated with achievement, persistence, and tenacity in educational settings (Bandura, 1986; Gore, 2006; House, 2000; Schunk, 1981; Zimmerman, 1989). In their meta-analysis of research in educational settings Multon et al. (1991) found that self-efficacy was related to academic performance and persistence. Their findings indicated that the different measures of academic performance used in the various studies could be categorized into standardized tests, classroom-related measures, or basic skill tasks. In the meta-analysis by Robbins et al. (2004), academic self- 
efficacy was the best predictor for GPA. Self-efficacy had a positive effect on student academic outcomes.

Self-efficacy had been studied by others in the context of students classified as at-risk (Alfassi, 2003), pre- or post secondary educational levels (Chemers et al., 2001; Gore, 2006), and ethnicity (Solberg et al., 1993). The results of these studies indicated that self-efficacy accounts for enough variance and significant correlations to merit inclusion as a variable in the current study. The application of self-efficacy theory to academic motivation is also supported by this literature review. Researcher's attempts to account for an explanation of academic performance have resulted in numerous studies that have used self-efficacy as a predictor, or other variable. Research findings have indicated that positive selfefficacy beliefs influence students' academic performance. Academically successful students possessed a high level of self-efficacy, regardless of the educational level at which they were tested.

As confirmed by this literature review, the majority of the studies have been conducted in disciplines other than in the health sciences, delimited to correlation with classroom-related measures, basic skill tasks, or GPAs, and 
using samples from only one source. This study will build on previous research on self-efficacy and academic achievement. It will also provide more information on the relationship between students' success on a licensure or certification exam of a health science profession and perceived self-efficacy of college-age students. Finally, findings from this study have the potential to contribute to the research by providing more information about selfefficacy and its relationship to success among a diverse student sample enrolled in health science programs in different community colleges in one state.

\section{Social Support}

For purposes of this study, social support is defined as helpful behavior provided to students by the instructor. In that light, social support has been demonstrated to be a successful predictor in a variety of settings, especially in healthcare and in education. There is limited information related to social support as related to success on achievement or high stakes tests. This section examines how social support, a psychosocial variable, has contributed to successful interventions in academic and non-academic achievement. 
Social Support as a Psychosocial Variable

Social support has been seen to be a powerful variable in health and wellness settings. Studies have documented the inquiry into social support in both disease and healthrelated topics, regardless of age groups. For example, researchers have explored topics such as social support of adolescent first time mothers (Dormire, Strauss, \& Clarke, 1989), divorced women with children (Duffy, 1989), individuals who have experienced myocardial infarction (Miller, McMahon, \& Garrett, 1989), and elders with diminished vision (Foxall, Barron, Von Dollen, Shull, \& Jones, 1994). These studies have yielded positive results when social support was provided.

Additional studies on social support have found it to be an important factor in predicting positive outcomes in health and wellness. It has been studied as a buffer against life stressors and an agent that promoted health and wellness by Vaux (1988). Other researchers have found that social support can predict positive outcomes in health and wellness for both children and adolescents (KilpatrickDemaray \& Kerres-Malecki, 2003; Patrick, Ryan, Alfeld-Liro, Fredericks, Hruda, \& Eccles, 1999). The construct of social support from parents, peers, and teachers has also been 
recognized to be a protective factor for children and teens against substance abuse (Benard, 2004).

Social Support and Student Motivation

Research on social support has linked it to motivation in school. All studies found for review focused on students in the $\mathrm{K}-12$ school systems, thereby limiting the generalizability of the study findings. Expanding on the student motivation benefit of teacher provided social support, there is strong evidence that students are more successful with teachers who support their autonomy (Reeve, 2002). Reeve conducted a meta-analysis of studies published between 1980 and 2000 that compared autonomy-supported with controlling teachers to determine if there was a difference in the educational benefits. The study results clearly indicated that students benefited in at least one of the following nine ways when teachers supported their autonomy; higher academic achievement, higher perceived competence, higher self-esteem, higher rates of retention, greater conceptual understanding, greater creativity, greater flexibility in thinking, more positive emotionality, or more active information processing (Reeve, 2002). These conclusions are also supported by Eccles and Midgley 
who indicated that student motivation was partly dependent on the quality of the student-teacher relationship.

Although helpful in determining that teacher support improved educational outcomes, the studies included in the meta-analysis were limited by their sample characteristics (age group), educational setting (elementary school), and there were no independent standardized tests to measure the educational outcomes (Reeve, 2002). This current study included the measurement of a national certification exam to determine how instructor support will predict academic success for community college students.

According to Furrer and Skinner (2003), because of the many roles that teachers play, such as disciplinarian, pedagogue, potential attachment figure, and final arbitrator of the student's level of performance, studentteacher relationships were very powerful. Earlier research has shown that teachers influenced student motivation through classroom reward structure (Ames \& Ames, 1984), classroom organization (Rosenholtz \& Wilson, 1980), and curriculum (Renninger, Hidi, \& Krapp, 1992). Wentzel (1997) reported that middle school teachers caring (social support) predicted changes in motivational outcomes over 2 years. All of these studies were limited to their sample 
age groups and settings; None included community colleges in their setting or health science students.

Wentzel's (1998) second study included 167 sixth-grade students from a middle school to examine ways in which supportive relationships with teachers are related to young adolescents' motivation at school. She found that teacher support was a positive predictor of both class $(R=.18$, $p<.05)$ and school interest $(R=.33, p<.001)$, therefore concluding that perceived support from teachers was related to students' grades. Consequently these findings were limited to middle school aged children. Furthermore, no measure of academic achievement was included, specifically not a standardized test.

Student motivation was also affected by how teachers (faculty) interacted with their students. Hardre and Reeve (2003) developed a motivational model that determined persistence in high school and concluded that students' motivation can be supported in the classroom by autonomysupportive teachers. Thus teachers can influence student performance by being autonomy-supportive teachers. The study results indicated that students' perceptions of how autonomy supportive their teachers were in the classroom would predict students' intentions to persist in school. 
If students' perceptions were low, the researchers concluded that the students would begin to develop intentions to dropout. Hardre and Reeve's (2003) study is important because the findings indicated that teachers provided social support to their students which encouraged persistence. However its generalizability was limited because data were collected using a cross-sectional rather than a longitudinal research design.

Legault, Green-Demers, and Pelletier (2006)

investigated the role of social support in academic amotivation (the absence of motivation) of high school students, proposing that academic attitudes and behaviors were strongly influenced by core social agents in the student's environment, namely, friends, parents, or teachers. They assessed the interrelations of the three forms of interpersonal support furnished by friends, parents, and teachers within the student's social environment and the dimensions of academic amotivation. The participants of the study were 741 Canadian francophone high school students.

A result of the Legault et al. (2006) study indicated that teachers' competence support was negatively associated with amotivation due to ability beliefs, effort beliefs, 
and task characteristics $(-.18,-.24,-.22)$. The researchers concluded that students were amotivated (not motivated) for different reasons, all of which were generated from inadequate social support. Most importantly, the lack of competence support from teachers was associated with low-ability beliefs, which ultimately, was associated with low academic self-esteem and poor performance. When students looked to their teachers for information that supported their academic abilities but did not get it, there were negative results. The study emphasized the magnitude of teachers providing students with information and feedback to reinforce student academic motivation. The findings linked social support from the teacher with student motivation in school. However the findings were limited by the study's lack of a measurement of academic achievement and generalizability due to the sample and setting

Social Support and Student Achievement

Two studies were found in the literature, one using students in the $\mathrm{K}-12$ system and the other using college freshmen, linking social support to student achievement. To determine how teacher social support facilitated students' achievement, Yeung and McInerney (2000) used 893 middle and 
high school students from a city in Arizona. Correlation between students' achievement (GPA) and the positive factors (peers, parents and teachers) was significantly positive $(p=.41, .36$, and .49 respectively, with $p<.05)$. The importance of this study is that encouragement (social support) from teachers facilitated students' achievement behavior, but its generalizability is limited due to the sample. Also, the measure of academic achievement used in the study was not a standardized test. When investigating the effectiveness of cognitive and psychosocial variables to predict first-year students' GPA (achievement) and retention, Ting and Robinson (1998) used 2,600 Caucasian and African American college freshmen students in a public university. Out of the two predictor variables, high school GPA and availability of a strong support person (social support), high school GPA was the most powerful single predictor for all students. There was also significant correlation between the strong support person variable and the Fall semester GPA for all students $(.05, p<.05)$. The multiple regression model for all students that best predicted the Fall semester GPA included both cognitive and psychosocial variables $(R=.45)$ which implied that both types of variables can predict student 
success in college. The correlation between the variable strong support person and the Fall semester GPA provided reason for including social support in this study to investigate its correlation with the national Registry exam. The findings of the Ting and Robinson study were limited by the lack of generalizability due to using one source of subjects and not including a measure of achievement using a standardized test score. Social Support and Academic Performance There are studies that document a link between social support and academic performance. Research on this topic focused on students in higher education which is relevant to the current study. Barnes, Potter, and Friedler (1983) conducted two studies using U.S. Coast Guard Academy cadets as the subjects to examine the effect that different types of interpersonal stress have on the contribution of intellectual abilities on the execution of difficult and intellectually demanding tasks. The first study was done to compare the effects of stress with commanding officers (CO), instructors, parents, and peers on academic performance. The hypotheses that stress with peers and commanding officers affected the ability of the SAT Quantitative subtest scores to predict academic performance 
of the cadets was supported by the regression analysis. However in this Barnes et al. (1983) study, stress in the relationship with either the cadets' parents or instructors did not interact with intellectual ability.

In their second study, Barnes et al. (1984) included cadets in the final two years of the Academy who were enrolled in a psychology course. The cadets' performance in the second study did not differ significantly from the first $(t=.25, d f=184, n s)$. The factor analysis of the stress questionnaire items yielded four orthogonal factors with eigen values greater than one. The items loading highest on these factors pertained to the following in rank order; Peer, Instructor, Commanding Officers (CO), and Parental Stresses. The results of the Barnes et al. second study showed that stress with instructors and parents (no social support) reduced the cadets' academic performance. The Instructor stress and GPA correlation was -.319 $(N=89, p<.001)$. The results indicated that stress with academic instructors affected intellectual performance differently than stress from other sources, specifically Cos and peer. The findings were limited by the study's lack of generalizability due to the selection of subjects from a highly selective setting. 
Furthermore, the dependent measure was the cumulative GPA for one semester, not a standardized test.

In a more recent study, Coffman and Gilligan (2002) used 94 first-year students from one university to determine which variables impacted students' adjustment to college and ultimately their academic and social success. A significant positive correlation was found between perceived social support and life satisfaction, $r(92)=.604, p<.01$, and between self-efficacy and life satisfaction, $r(92)=.439, p<.01$. The results of the hierarchical multiple regression analysis, in which social support, self-efficacy, and stress were all entered, was significant, $r(92)=.644, p<.01$, and accounted for $41 \%$ of the variance in life satisfaction. Social support accounted for a significant amount of the variance $(\beta=.609$, $R_{\text {Total }}^{2}=.371, p<.01$ ). Coffman and Gilligan's (2002) study has relevance because its results indicated that social support, self-efficacy, and stress will affect life satisfaction, and ultimately a student's academic and social success in college. However it was limited because the study included no measure of academic achievement in the form of a standardized test. 
Carney-Crompton and Tan (2002) compared traditional and nontraditional university students in their study on support systems and academic performance. The sample consisted of 63 full-time female students from undergraduate social humanities classes in a Canadian university who volunteered to participate in the study. The researchers concluded that nontraditional students performed at a higher academic level than traditional students $(t=2.95, p<.01, d f=31)$ despite having more stressors and fewer sources of support. Furthermore, the traditional participants reported greater numbers of individuals available to them for emotional and instrumental support than did nontraditional participants. Carney-Crompton and Tan's (2002) study was limited due to the very small sample size and basing academic achievement on one course grade. Additionally, the survey instrument did not include faculty as a support source option. DeBerard, Spielmans, and Julka (2004) examined how social support predicted freshmen academic achievement using 204 students enrolled in introductory psychology and sociology classes from a private university. Social support was found to be significantly correlated with cumulative GPA $(.19, p<.05)$. The linear regression model, which 
included social support, to predict cumulative GPA was statistically significant $(F=23.80, d f=10,185$; $p=.00)$. This study is noteworthy because social support was a significant independent predictor of academic achievement. However their findings were not generalizable due to the limited setting and convenience sample.

There are few studies that predict student achievement in college using variables from both the cognitive and noncognitive domains. Ting (1997) conducted a study to determine how well select cognitive and noncognitive variables could predict college GPA and first-year retention for a cohort of specially admitted Caucasian students. The setting for this study was a state university and the sample consisted of freshmen $(N=124)$ who were specially admitted to the university on probation. The variables included in Ting's study were high school rank, ACT scores, and the psychosocial variables taken from the Noncognitive Questionnaire (NCQ; Tracey and Sedlacek, 1984). GPA was used to indicate academic performance and the number of academic units for retention. The study results indicated that the psychosocial variable, strong social support person, was significantly related to the college GPA in the first and second semesters and for the 
cognitive variables, ACT Verbal scores, ACT Composite scores, and high school rank were related to GPA in the first year.

Ting's (1997) findings indicated that cognitive and psychosocial variables are important in predicting academic performance and retention of specially admitted Caucasian students in college. Most importantly, Ting concluded that a combination of the two variables may be a better predictor of academic success for this sample. Delimiting factors of Ting's study included a sample that was small in size and selected from one institution. Ting did not differentiate who actually was the strong support person designated by the participants when the NCQ was completed. Ting's study is beneficial because it included variables from both the cognitive and noncognitive categories and they both were shown to be significant predictors of academic success in college. Summary of the Literature on Social Support The literature review of social support research supports the role of social support in academic motivation and success (Hardre \& Reeve, 2003). Social support from faculty has a positive effect on student academic outcomes. It has been studied in the context of high school students 
(Legault et al., 2006) and teacher support (Reeve, 2002; Yeung \& McInerney, 2000) and has been found to account for sufficient variance in academic motivation.

There are no studies that indicated how social support from the community college faculty affects student achievement on a standardized certification exam in the health science domain. Most studies have been conducted in disciplines other than in the health sciences (Barnes, et al., 1983; Ting \& Robinson, 1998), delimited to correlation with only one or two final course grades (Carney-Crompton \& Tan, 2002; Yeung \& McInerney, 2000), and using samples from only one source (Coffman \& Gilligan, 2002; Ting, 1997; Ting \& Robinson, 1998).

The current study will build upon previous research on social support and academic achievement. It has the potential to provide more information on the relationship between success on a health science profession's certification exam and social support received from faculty. It will also contribute to the current research literature on social support and its relationship to success among a diverse student sample enrolled in health science programs offered by all community colleges located in the state of Florida. 
The evidence presented provides sufficient reason for including social support in this study.

\section{Summary}

This chapter presented a review of the literature regarding the strengths of both cognitive and noncognitive variables to predict successful academic outcomes. A total of 48 research studies were critiqued in the literature review. Twenty-one of these studies used Bandura's concept of self-efficacy and 18 were based on social support. Only one study included both self-efficacy and social support as variables. While 10 of the studies used course grades as the outcome variable, only 6 studies used final course grades as the predictor variable. There were only seven studies that used a health science professional certification or licensing exam as the outcome variable. None of the studies applied logistic regression as the inferential statistic despite using a pass or fail outcome on the certification or licensing exam. All of the studies were quantitative and conducted in a variety of settings. Five studies were conducted in a community college setting while 8 were conducted in a university. Only 2 of the studies included the national Registry exam as the outcome variable. These studies did not produce a prediction model 
that is applicable to the current radiography curriculum and national Registry exam.

Research has shown the success of using the cognitive variables, GPA, course grades, progression points, and the noncognitive variables, self-efficacy and social support independently from one another to predict successful academic outcomes. However there have been few attempts to combine these variables into one model to predict the success of community college health science program graduates on a standardized national certification examination. This study used a combination of these cognitive and noncognitive variables to examine their predictive merits on the national Registry exam in radiography using the 2008 graduates from Florida community college radiography programs. Chapter 3 outlines the methods used to complete the study. 


\section{CHAPTER III}

\section{RESEARCH DESIGN AND METHODS}

This was an exploratory study using a predictive model for passing the national Registry exam for 2008 graduates of Florida community college radiography programs. The predictor model was based on four specific variables: (a) grade point averages (GPAs) at two progression points; (b) final grades in five program courses; (c) perceived selfefficacy; and (d) social support. The framework for this study was presented in chapter 2 .

\section{Study Design}

The design for this study was twofold. It was a retrospective predictive study that relied on academic data collected from study participants using the self-report method. The study was also exploratory, where the perceptions of students' success on the national Registry exam were collected using a noncognitive survey developed and piloted in this study. Of particular interest were self-efficacy and social support.

Research Questions

This study was conducted to answer the following four research questions: 
1. To what degree do the cognitive variables, end of first year GPA and end of program GPA, predict national Registry exam success for graduates from Florida community college radiography programs?

2. To what degree do the cognitive variables, final grades in the program courses RTE 1418, 1503, 1513, 1613, and 2385, predict national Registry exam success for graduates from Florida community college radiography programs?

3. To what degree does the noncognitive variable, selfefficacy, predict national Registry exam success for graduates from Florida community college radiography programs?

4. To what degree does the noncognitive variable, social support, predict national Registry exam success for graduates from Florida community college radiography programs?

Each variable's ability to predict success (pass) was examined independently of one another. The degree of predictability was measured for each of the independent variables using logistic regression at the .05 significance level. 
Setting

The setting for this study was all florida community colleges that sponsored a Radiography program $(N=19)$ who agreed to permit their students to be invited to participate. All programs required 77 credits and awarded an Associate of Science degree in Radiography. The state curriculum framework outlined the competencies for the program. All programs measured and monitored outcomes of student success using the national Registry examination first-attempt pass rate.

Participants

The participants for this study were from community college radiography programs in Florida who were expected to graduate in 2008 and to take the national Registry exam by the end of September 2008. The original sample consisted of 209 students, but in the end there were only 175 because not all of the participants returned the instrument designed to collect data in the second phase. All participants included in the final sample had a complete file that consisted of (a) a completed questionnaire designed by the investigator to determine self-efficacy and social support; (b) all self-reported course grades, and (c) self-reported results on the national Registry exam. 
Student success was operationalized for this study as "first attempt results", therefore only first-attempt results (pass or fail) on the national Registry exam were used in this study.

Protection of Human Subjects

Protection of human subjects was assured by following the guidelines of Florida International University Institutional Research Board (IRB). Approval was obtained from Florida International University's IRB where the research was carried out. Prior to data collection, additional IRB-approved protocol, that included obtaining and gaining permission from the community colleges where the participants matriculated, was also followed. Subjects were assigned an identification number when they returned the questionnaire that measured self-efficacy and social support. Confidentiality was maintained in that all data were de-identified; that is participants' community college, national Registry exam results for each college cohort.

Procedure

Instrumentation

Data for the study were collected in two phases. The initial phase collected data on the two noncognitive 
variables, self-efficacy and social support through a questionnaire developed by the principle investigator. The study instrument, a questionnaire, was based on three questionnaires found in the literature that measured perceived self-efficacy and/or social support.

Study questionnaire. The questionnaire items used to measure perceived self-efficacy in this study were adapted from the 10-item General Perceived Self-Efficacy Scale developed by Schwarzer and Jerusalem (1993). The authors of this scale have granted permission to use this scale or portions of it for research purposes (General Perceived Self-Efficacy Scale, July 10, 2007). The questionnaire items used to measure perceived social support were adapted from the 29-item Noncognitive Questionnaire designed by Sedlacek (2004) and the 60-item Child and Adolescent Social Support Scale (CASSS) by Malecki, Demaray, and Elliott (2000). Permission to use items from these two validated questionnaires was granted by the original researchers (W. Sedlacek, personal communication, March 26, 2007; C. Malecki, personal communication, July 12, 2007). Phase 1. The questionnaire began with a cover letter giving the title of the research, an explanation of its purpose, participant's obligations, and disclosure related 
to consent and anonymity (See Appendix A). The instrument consisted of 14 items, seven to measure self-efficacy and seven to measure social support (See Appendix B). Respondents were asked to rate their response to each item using a 4-point Likert scale. Scores for self-efficacy and social support were derived by adding the ratings for each of the items representing that dimension. The two items used to measure self-efficacy and social support in the questionnaire are presented with their corresponding item numbers in Appendix $C$. The first phase questionnaire also included items to collect demographic data and contact information to facilitate completion of the second phase of data collection.

Phase 2. Each participant's final grades in the radiography curriculum courses and their national Registry exam results (pass/fail) were collected in the second phase of data collection and recorded using an instrument that was specifically developed by the principle investigator for this purpose (See Appendix D). Participants provided all data using the self-report method in the second phase. Pilot of the Instrument

Because the questionnaire had not been validated, a pilot study was necessary. Prior to conducting the pilot 
study, a team of three experts reviewed the PI-developed questionnaire to assure that the directions were understandable, that each item was clear, and that the terminology was comprehendible. The PI used their feedback to revise and refine the directions to participants and the survey items.

A community college outside the state of Florida that sponsored a radiography program was selected as the setting for the pilot study to serve as a comparison control. After permission was obtained from the sponsoring institution, students who were in the same 2008 graduation cohort as the intended study population were asked to participate in the survey. The pilot sample included 34 participants and was conducted during the 2007 fall semester. The returned surveys were entered in an SPSS worksheet and statistics were run to determine survey validity. Cronbach's alpha for the questionnaire in the pilot sample was .84 ; that is greater than Nunally's (1978) recommendation for a minimum level of .70 . Therefore, the 14 items on the developed scale to measure self-efficacy and social support were internally consistent as indicated by the high level of correlation between the items that make up the scale. 
Data Collection

After the questionnaire was determined to be reliable, copies were distributed to each director of the Florida community college radiography programs for Phase 1 of data collection. The radiography program directors received instructions on how to distribute the questionnaires to students following procedures routinely used by each college when gathering student feedback on course instructors. Faculty were not present in the room during the collection of data.

Using this method, the questionnaire was distributed to all students in the 2008 graduating cohort at a time most convenient for the faculty during the second to last semester of the program. A pre-addressed envelope was provided to each site to return completed surveys to the PI. All collected data were entered into a specifically designed database by the PI.

Data collection for Phase 2 was implemented 5 weeks after graduation to allow study participants sufficient time to take the national Registry exam and receive their score results. At the end of 5 weeks, the study instrument was sent to each participant who completed the data collection during Phase 1. 
Additional Phase 2 data collection included course grades relevant to the radiography curriculum and program GPAs. Program GPAs were calculated using all completed courses at the end of the first year and the end of the program. Appropriate data for each participant who returned the second questionnaire were added to the SPSS data file. Data Processing and Analysis

The data collected were stored in a computerized file, transformed, and analyzed as described below.

Raw Data File. The responses contained in the original 209 surveys, plus the 34 surveys from the pilot, were transferred to a computerized data file using SPSS, the software package used for statistical analysis in this study. The raw data file contained a total of 33 columns. The first column was used to identify each participant. Columns two to eighteen indicated the responses to the noncognitive questionnaire. The next five columns were used to record the final grade for each of the five selected courses used to predict success on the national Registry Exam. Columns 24 and 25 were used to record the end of the first year GPA and end of the program GPA respectively. Column 26 was used to record the participant's firstattempt score results on the national Registry exam. 
The next two columns were used to record the scores for self-efficacy and social support. The final five columns were used to record the recoded variables for the final grade for each of the five selected courses. Missing responses were codified using the code of 0 .

Data Transformations. The data required two transformations before the analyses could be completed. The first transformation consisted of the creation of variables in that a score was calculated to measure each participant's self-efficacy and social support. The score for each of the two noncognitive variables was computed by selecting the questionnaire items that were identified to measure the appropriate variable and calculating the sum of the values assigned to the actual student response. The second transformation required a recoding of the letter grade received in all five selected courses. The recoded data for the final course grades were based on the Florida International University's 4.0 Grading Scale (Undergraduate registration policies, n.d.).

Data Analysis. Data were analyzed using version 15.0 of the Statistical Package for the Social Sciences (SPSS, 2008). Retrospective correlation with Pearson product moment correlation coefficients (Pearson $r$ ) were calculated 
for each of the predictive variables along with the national Registry exam results. Logistic regression analysis was used to identify the cognitive and noncognitive predictors of success on the national Registry exam. Both the enter method and the backward stepwise method were used to analyze the data since they differ in the way they build the regression model and on the research basis.

The enter method forces all available predictor variables into the equation whether or not they are significantly related to the dependent variable. This method is preferred when selecting models on a theoretical basis (Garson, 2008); however this study was not conducted to test theory. The enter method was used to compare its results to those of the stepwise method because according to Ryan (1997), the results from the stepwise regression may be misleading since not all possible subsets are considered.

The backward stepwise method was used to analyze the variables because the study was strictly predictive and exploratory. However since this method runs the risk of modeling noise in the data (Garson, 2008), the results were compared with those obtained from the enter method. 
The backward stepwise method begins with a model that includes all of the independent variables. Variables not contributing to the equation are removed one at a time. In SPSS, this method may produce more than one model. The final model produced in the backward stepwise method is the last step model because adding another variable would not significantly improve the model. Since Menard (1995) indicates that the final model is the best model, the results from the final model or the last step will be reported and used to address each research question. The backward logistic regression option available in SPSS was used to run the data for this study because it utilizes the likelihood ratio test.

Logistic regression includes the use of many statistics to report and interpret data. The following statistics are reported in chapter 4; Hosmer-Lemeshow Goodness of Fit Test, -2 Log Likelihood value, Odds Ratio, Cox and Snell R Square, Nagelkerke R Square, Sensitivity, Specificity, Beta Weight, and Wald. Each statistic is described below, based on the SPSS Survival Manual (Pallant, 2007), unless otherwise referenced.

Hosmer-Lemeshow Goodness of Fit Test. This test is the most reliable test of model fit currently available in 
SPSS. Poor fit is indicated by a significance value less than .05, therefore to support the model, a value greater than .05 is desired.

-2 Log Likelihood ( $-2 L L$ ) value. Overall significance is tested in SPSS using the Model Chi-square which is derived from the likelihood of observing the actual data under assumptions that the model that has been fitted is accurate (Overall significance, 2008). The reported value is -2 times the log (base e) of this likelihood and can be used for assessing the significance of a logistic regression. The $-2 \mathrm{LL}$ is the recommended test statistic to use when building a model through the backward stepwise method (Likelihood-ratio test, 2008).

Odds Ratio (OR). According to Tabbachnick and Fidell (2007), the odds ratio represents "the change in odds of being in one of the categories of outcome when the value of a predictor increases by one" (p.461). This significant value is used to calculate the likelihood that a student will pass than fail the national Registry exam on the first attempt. Howell (2007) cites two reasons why odds ratio is important; a) it can be calculated in situations where true risk cannot, and b) taking the natural log of the odds ratio provides a useful statistic in logistic regression. 
Cox and Snell $R$ Square and the Nagelkerke $R$ Square. These two values provide information regarding the usefulness of the model. They are an indication of the amount of variance in the dependent variable that is explained by the model, between 0 , minimum value, and 1 , maximum value. These two measures are described as pseudo $R$ square statistics rather than the true $R$ square value provided in a multiple regression. The two values describe the lower and upper per cent of variability explained by the independent variables. The Cox and Snell $R$ Square is based on the log-likelihood of both the old and new models as well as the sample size. Since this statistic never reaches its theoretical maximum of 1 (maximum value always less than 1), Nagelkerke (1991) suggested an amendment to the Cox and Snell $R$ Square formula to produce a value between 0 and 1 . The latter is usually preferred for this reason. Nagelkerke value is usually higher than the cox and Snell value. The two measures differ in their computation and therefore the end results, but they are collectively seen as somewhat the same. In their interpretation, Cox and Snell R Square and the Nagelkerke R Square are similar to $R^{2}$ in linear regression. 
Sensitivity. This value describes the percentage of the group that has the characteristic of interest that has been accurately identified by the model (true positives). Specificity. This value describes the percentage of the group without the characteristic of interest that is correctly identified (true negatives).

Beta Weight (B). The $B$ value is equivalent to the $B$ value provided in a multiple regression analysis. It is used in the equation to calculate the probability of a case falling into a specific category. Whether the value is positive or negative will determine which way the direction of the relationship between the independent and dependent variables. In logistic regression it represents the change in the logit of the dependent variable that is associated with a one-unit change in the predictor variable. Wald. The Wald test provides information of the variables used in the equation, specifically, their contribution or importance to the predictor variable. The importance is determined by the Wald Test's level of significance reported. A value less than .05 indicates a variable that contributes significantly to the predictive ability of the model. 
Therefore, to address the four research questions, logistic regression analysis was done using the enter method and the backward stepwise method. The two GPAs were entered into a logistic regression analysis along with the two noncognitive variables, self-efficacy and social support, to produce two models. Next all five of the final grades in the selected program courses (RTE 1418 Radiographic Exposures, RTE 1503 Radiographic Procedures I, RTE 1513 Radiographic Procedures II, RTE 1613 Radiologic Physics, and RTE 2385 Radiation Safety \& Protection) were entered into a logistic regression analysis along with the two noncognitive variables, self-efficacy and social support, to produce two models. A total of four logistic regression models were produced to address the research questions.

The data were analyzed using three additional statistics as well. First, the expected proportion by chance was calculated for comparison with the predicted proportion of students passing the national Registry exam based on the models. Second, independent t-tests were conducted to determine if there were group differences between performance on the national Registry and the four significant predictor variables; end of program GPA, 
RTE 1418, RTE 1613, and RTE 2385. Third, to cross validate the results of the logistic regression stepwise method, a random sample (50\% of the cases) was selected and another logistic regression was done to see if the variables entered into the logistic regression would correctly predict passing the national Registry Exam.

\section{Summary}

This study examined the predictive merits of grade point averages (GPAS) at two progression points in the radiography curriculum, course grades in five specific program courses, students' perceived self-efficacy and social support on the national Registry exam for 175 of the 2008 graduates of Florida community college radiography programs in order to develop a predictive model for passing the national Registry exam. This chapter described the development of an instrument to measure self-efficacy and social support and the design of the study. Logistic regression analysis was used to analyze the data using the enter and backward stepwise methods. The results of the data collection are reported in chapter 4. 


\section{CHAPTER IV}

\section{FINDINGS}

This study examined the predictive merits of (a) grade point averages (GPAs) at two progression points, (b) final grades in five program courses, and (c) perceived selfefficacy and social support, on the national Registry exam for radiography graduates. The study examined 2008 data from community college radiography programs $(N=19)$ throughout the state of Florida. The findings of this study are reported in this chapter. The predictive model for passing the national Registry exam based on four variables is reported.

Sample

Florida community college radiography programs were used as the setting for this study. The original sample included 209 students who were beginning the second year of the program. Because 34 students did not return the final data form after the second request, they were eliminated from the study. A total of 175 students submitted complete data forms, thus they were included in the study, yielding a return rate of $83.7 \%$. Only data on the 175 students will be reported. 
The demographics of the sample are included in

Table 1. The sample was mostly female (60\%), while the largest percentage of race/ethnicity was White (44\%), followed by Hispanic (23.4\%), and Black (18.9\%).

Table 1

Demographics of Sample

\begin{tabular}{llrr} 
Category & Groups & Count & Percent \\
\hline \multirow{3}{*}{ Gender } & Male & 70 & \\
& Female & 105 & 60.00 \\
Ethnicity & Asian/Pacific Islander & 8 & \\
& Black & 33 & 18.90 \\
& Hispanic & 41 & 23.40 \\
& White & 77 & 44.00 \\
& Other & 16 & 9.10 \\
Age & $20-25$ & 69 & 39.43 \\
& $26-31$ & 56 & 32.00 \\
& $32-37$ & 21 & 12.00 \\
& $38-43$ & 19 & 10.86 \\
& $44-49$ & 7 & 4.00 \\
& 50 and over & 3 & 1.71 \\
\hline \multirow{2}{*}{ Total } & & & \\
& & & \\
& & &
\end{tabular}

Participants were asked to report age using their birth year. The two most commonly reported birth years were $1980(n=17)$ and $1986(n=16)$. Since there were 31 different age groups reported in the sample, age was summarized using ranges. Table 1 includes a breakdown of 
participants by ranges of age. The largest percentage of students were between the ages of 20 and $31 \quad n=125$, $71.43 \%)$

Pearson Product-Moment Correlation analysis was used to measure the strength of the association between the dependent variable (national Registry exam) and all of the independent variables; (a) grade point averages at two progression points (end of first year and end of program); (b) final grades in five program courses (RTE 1418 Radiographic Exposures, RTE 1503 Radiographic Procedures I, RTE 1513 Radiographic Procedures II, RTE 1613 Radiologic Physics, and RTE 2385 Radiation Safety \& Protection); and (c) perceived self-efficacy and social support. Correlations between all independent variables were significant $(p<.01)$ with each other except for selfefficacy and social support. All independent variables except self-efficacy and social support correlated with success on the national Registry exam $(p<.01)$. The least effective predictor of the national Registry exam was RTE 1503, $r=.299, p<.001$. The strongest predictor of the national Registry exam was end of the program GPA, $r=$ $.550, p<.001$. The correlation between self-efficacy and social support was significant, $r(175)=.186(p<.05)$, 
but neither were significantly correlated with any of the other independent variables. The Pearson Product Moment Correlation Coefficients between the independent variables and dependent variable are presented in Table 2. The actual (observed) pass rate on the national Registry exam for the sample was $86 \%(150 / 175)$ and the fail rate was $14 \%$

$(25 / 175)$. The expected pass rate by chance was $76 \%$ based on these results. The Chi-Square results were $\mathrm{X}^{2}(1, N=175)=$ $17.05, p<.05$.

The research questions were answered with logistic regression analyses using the enter and backward stepwise methods. A logistic regression was completed rather than a linear regression because the dependent variable was a dichotomous value. Both the enter and backward stepwise methods were used in the study because the literature differs on the better method to obtain the most accurate results (Garson, 2008; Menard, 1995).

Two different combinations of the independent variables were entered into the logistic regression models to answer the research questions. The two GPAs (end of first year and end of program), self-efficacy, and social support were entered together to answer research questions one, three and four. All five RTE courses, self-efficacy, 
and social support were entered together to answer research questions two, three and four.

Table 2

Correlations Between Predictor Variables and National Registry Exam

Variable

r

P

End of the First Year

$.495^{*}$

.000

End of the Program

$.550 *$

.000

RTE 1418 Radiographic Exposures

$.489 *$

.000

RTE 1503 Radiographic Procedures I

$.299 *$

.000

RTE 1513 Radiographic Procedures II

$.338 *$

.000

RTE 1613 Radiologic Physics

.442 *

.000

RTE 2385 Radiation Safety \& Protection

$.409 *$

.000

Self-Efficacy

$-.059$

.442

Social Support

.043

.574

${ }^{*} p<.01(2$-tailed $)$.

Findings Pertinent to Each Research Question

Research Question \#1

To what degree do the cognitive variables, end of first year GPA and end of program GPA, predict national Registry exam success for graduates from Florida community college radiography programs? 
Logistic regression was used to determine the probability of a student passing the national Registry exam on the first-attempt using the independent variable GPA measured at the end of the first year of the program and again at the end of the program. The data were evaluated using the enter and backward stepwise methods.

First, both GPAs, self-efficacy, and social support were entered into a logistic regression using the enter method. The predictive model for this logistic regression using the enter method was statistically significant, $\mathrm{X}^{2}(4, N=175)=51.769, p<.001$. The Hosmer and Lemeshow Test results, $x^{2}(8, N=175)=3.039, p=.932$, indicated that the goodness of fit test was satisfactory. The -2 Log Likelihood value was 91.771 for the overall evaluation of this model.

As indicated in Table 3, the End of the Program GPA (GPA2, $p=.015$ ) variable was the only significant variable in this model with an odds ratio (OR) of 27.732. The End of the First Year GPA (GPA1, $p=.212$ ), self-efficacy (SESCORE, $p=.319)$, and social support (SSSCORE, $p=.900)$ were not significant. This model explained between $25.6 \%$ $($ Cox and Snell $R$ square $=.256)$ and $45.8 \%$ (Nagelkerke $R$ 
square $=.458$ ) of the variance in passing the national Registry exam on the first-attempt.

As indicated by the data for this model that only included the significant variable, end of program GPA, it was more difficult to predict those who failed than the students who passed the national Registry exam (Table 4). The model predicted $44 \%$ of the students who failed the national Registry exam and successfully predicted $97.3 \%$ of those who passed. As Table 4 indicates, this model correctly classified $89.7 \%$ of graduates overall. Table 3 Logistic Regression Using the Enter Method

$95 \%$ C.I.

\begin{tabular}{lcccccccc} 
Variable & $B$ & SE B & Wald & df & SIG & OR & Lower & Upper \\
\hline GPA1 & 1.764 & 1.413 & 1.558 & 1 & .212 & 5.833 & .366 & 93.025 \\
GPA2 & 3.323 & 1.361 & 5.962 & 1 & $.015^{*}$ & 27.732 & 1.926 & 399.242 \\
SESCORE & -.161 & .162 & .993 & 1 & .319 & .851 & .620 & 1.168 \\
SSSCORE & -.025 & .199 & .016 & 1 & .900 & .975 & .661 & 1.439 \\
Constant & -11.425 & 4.446 & 6.602 & 1 & .010 & .000 & & \\
\hline
\end{tabular}

${ }^{*} p<.05$. 
Table 4

Classification Table for End of the Program GPA Using the Enter Method

Predicted

Observed

Fail

Pass

Total

\% correct

\begin{tabular}{lrrrr}
\hline Fail & 11 & 14 & 25 & $44.0^{\mathrm{a}}$ \\
Pass & 4 & 146 & 150 & $97.3^{\mathrm{b}}$ \\
\hline Total & 15 & 160 & 175 & \\
\hline
\end{tabular}

Note. Overall Percentage $=89.7$. ${ }^{\mathrm{a}}$ Specificity. ${ }^{\mathrm{b}}$ Sensitivity.

Next both GPAs, self-efficacy, and social support were entered into a logistic regression using the backward stepwise method which produced four steps. In the initial step, which included all four independent variables, the end of the program GPA (GPA2, $p=.015$ ) variable was significant, and the end of the first year GPA (GPA1, $p=.212$ ), self-efficacy (SESCORE, $p=.319$ ), and social support (SSSCORE, $p=.900$ ) were not significant. These results are exactly the same as those obtained using the enter method (Table 3).

The final predictive model (step 4) for this logistic regression was statistically significant, 
$\chi^{2}(1, N=175)=49.29, p<.001$. The Hosmer and Lemeshow Test results, $\chi^{2}(8, N=175)=4.85, p=.744$, indicated that the goodness of fit test was satisfactory. The -2 Log Likelihood value was 94.251 for the overall evaluation of this model. The end of the program GPA (GPA2) was the only independent variable left in the model. It made a statistically significant $(p<.001)$ contribution to the final model, with an odds ratio (OR) of 102.61 (Table 5). This final model explained between $24.5 \%$ (Cox and Snell $R$ square $=.245)$ and $43.9 \%($ Nagelkerke $R$ square $=.439)$ of the variance in passing the national Registry exam on the first-attempt.

Table 5

Logistic Regression Using the Backward Method

95\% C.I.

\begin{tabular}{lrrrrrrrr} 
Variable & $B$ & SE $B$ & Wald & df & SIG & OR & Lower & Upper \\
\hline GPA2 & 4.631 & .844 & 30.125 & 1 & $.000 *$ & 102.612 & 19.634 & 536.278 \\
Constant -13.729 & 2.757 & 24.797 & 1 & .000 & .000 & &
\end{tabular}

${ }^{*} p<.05$.

As indicated by the data in Table 6 for the final model, which only included the end of the program GPA (GPA2), it was more difficult to predict those who failed 
than the students who passed the national Registry exam. The end of the program GPA only predicted $36 \%$ of the students who failed the national Registry exam but successfully predicted $96.7 \%$ of those who passed. Overall, this model correctly classified $88 \%$ of graduates (Table 6). These results were very similar to those obtained using the enter method.

Table 6

Classification Table for End of the Program GPA Using the Backward Method

Predicted

Observed

$$
\text { Fail }
$$

Pass

Total

\% correct

\begin{tabular}{lrrrr}
\hline Fail & 9 & 16 & 25 & $36.0^{\mathrm{a}}$ \\
Pass & 5 & 145 & 150 & $96.7^{\mathrm{b}}$ \\
\hline Total & 14 & 160 & 175 & \\
\hline
\end{tabular}

Note. Overall Percentage $=88.0$. ${ }^{\mathrm{a} S p e c i f i c i t y . ~}{ }^{\mathrm{b}}$ Sensitivity.

Research Question \#2

To what degree do the cognitive variables, final grades in the program courses RTE 1418, 1503, 1513, 1613, and 2385, predict national Registry exam success for 
graduates from florida community college radiography programs?

Logistic regression was used to determine the probability of a student passing the national Registry exam on the first-attempt using the final grades from five courses included in the radiography curriculum as the independent variables. The data were evaluated using the enter and backward stepwise methods.

All five RTE courses (RTE 1418 Radiographic Exposures, RTE 1503 Radiographic Procedures I, RTE 1513 Radiographic Procedures II, RTE 1613 Radiologic Physics, and RTE 2385 Radiation Safety \& Protection), self-efficacy, and social support were entered into a logistic regression using the enter method. Table 7 matches the appropriate course number with its corresponding course title and variable code. The correlation of these courses to the national Registry exam is described in Appendix E.

The predictive model for this logistic regression was statistically significant, $\chi^{2}(7, N=175)=66.99$, $p<.001$. The Hosmer and Lemeshow Test results, $\chi^{2}(8, N=175)=6.913, p=.546$, indicated that the goodness of fit test was satisfactory. The -2 Log Likelihood value was 76.550 for the overall evaluation of this model. 
In this model the RTE1R (1418, $p<.001$ ), RTE4R (1613, $p=.014)$, and RTE5R (2385, $p=.044)$, variables were the only significant variables. The RTE2R (1503, $p=.368$ ), and RTE3R (1513, $p=.289)$, self-efficacy $(p=.667)$, and social support $(p=.946)$ were not significant. The RTE1R variable had the highest odds ratio $(O R=9.119)$, followed by RTE4R $(O R=3.381)$ and RTE5R $(O R=2.938)($ Table 8$)$. This model explained between $31.8 \%$ (Cox and Snell $R$ square $=.318$ ) and $56.8 \%$ (Nagelkerke $R$ square $=.568$ ) of the variance in passing the national Registry exam on the first-attempt.

Table 7

Radiography Curriculum Course Variables

Course

\begin{tabular}{lll}
$\begin{array}{c}\text { Variable } \\
\text { Code }\end{array}$ & Number & \multicolumn{1}{c}{ Title } \\
\hline RTE1R & RTE 1418 & Radiographic Exposures \\
RTE2R & RTE 1503 & Radiographic Procedures I \\
RTE3R & RTE 1513 & Radiographic Procedures II \\
RTE4R & RTE 1613 & Radiologic Physics \\
RTE5R & RTE 2385 & Radiation Safety \& Protection
\end{tabular}


Table 8

Logistic Regression Using the Enter Method for the Selected Courses, Self-Efficacy and Social Support

$95{ }^{\circ}$ C.I.

\begin{tabular}{lcccccccc} 
Variable & $B$ & SE B & Wald & df & SIG & OR & Lower & Upper \\
\hline SESCORE & -.072 & .167 & .185 & 1 & .667 & .931 & .671 & 1.291 \\
SSSCORE & -.014 & .199 & .005 & 1 & .946 & .987 & .661 & 1.458 \\
RTE1R & 2.210 & .607 & 13.269 & 1 & $.000 *$ & 9.119 & 2.776 & 29.955 \\
RTE2R & -.464 & .516 & .809 & 1 & .368 & .628 & .228 & 1.729 \\
RTE3R & .544 & .513 & 1.123 & 1 & .289 & 1.722 & .630 & 4.708 \\
RTE4R & 1.218 & .495 & 6.054 & 1 & $.014 *$ & 3.381 & 1.281 & 8.924 \\
RTE5R & 1.078 & .535 & 4.055 & 1 & $.044 *$ & 2.938 & 1.029 & 8.385 \\
Constant & -9.106 & 4.540 & 4.024 & 1 & .045 & .000 & &
\end{tabular}

Note. Selected Course Grades, Self-Efficacy and Social support.

${ }^{*} p<.05$.

As indicated by the data for this model, it was more difficult to predict those who failed than the students who passed the national Registry exam (Table 9). The model predicted $64 \%$ of the students who failed the national Registry exam and successfully predicted $96.0 \%$ of those who passed. Overall, this model correctly classified $91.4 \%$ of graduates. 
Table 9

Classification Table for RTE Courses 1418, 1613, and 2385

Predicted

Observed

Fail

Pass

Total

$\%$ correct

\begin{tabular}{lrrrr}
\hline Fail & 16 & 9 & 25 & $64.0^{\mathrm{a}}$ \\
Pass & 6 & 144 & 150 & $96.0^{\mathrm{b}}$ \\
\hline Total & 22 & 153 & 175 & \\
\hline
\end{tabular}

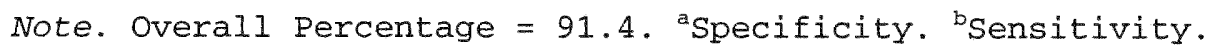

Next all five RTE courses (RTE 1418 Radiographic

Exposures, RTE 1503 Radiographic Procedures I, RTE 1513

Radiographic Procedures II, RTE 1613 Radiologic Physics, and RTE 2385 Radiation Safety \& Protection), self-efficacy, and social support were entered into a logistic regression using the backward stepwise method and produced five steps. In the initial step, which included all seven independent variables, the only significant variables were RTE courses $1418(\operatorname{RTE} 1, p<.001), 1613(\operatorname{RTE} 4, p=.014)$, and 2385 $(\operatorname{RTE} 5, p=.044) \cdot \operatorname{RTE} 1503(p=.368)$ and $1513(p=.289)$ were not significant, nor were the two noncognitive variables, self-efficacy $(p=.667)$, and social support $(p=.946)$. 
The final predictive model (Step 5) in the logistic regression for these independent variables was statistically significant, $\chi^{2}(3, N=175)=65.14, p<.001$, indicating that the model was able to predict which graduates would pass the national Registry exam on the first-attempt. This final model (Step 5) only included three RTE courses, 1418 (RTE1R), RTE 1613 (RTE4R), and RTE 2385 (RTE5R), all of which were significant in the initial model as well. In the final model, all three of these courses $(1418, p<.001 ; 1613, p=.007 ; 2385, p=.038)$ were significant at $p<.05$ (Table 10). The Hosmer and Lemeshow Test results for final step, $\chi^{2}(7, N=175)=5.27$, $p=.63$, indicated that the goodness of fit test was satisfactory. The -2 Log Likelihood value was 78.400 for the overall evaluation of this model. The final model containing RTE 1418, 1613, and 2385 explained between $31.1 \%$ $($ Cox and Snell $R$ square $=.311)$ and 55\% (Nagelkerke $R$ square $=.555$ ) of the variance in passing the national Registry exam on the first-attempt.

The overall classification accuracy for the final model was $91.4 \%$ (Table 11 ). In reviewing the data in Table 11 for the final model (Step 5), 68\% of the graduates who actually failed the national Registry exam were correctly 
predicted to fail and $95.3 \%$ of those who were predicted to pass actually passed.

Table 10

Logistic Regression for Step 5 Using the Backward Method

$95 \%$ C.I.

Variable

$B \quad S E B$ Wald df SIG

OR

Lower Upper

$\begin{array}{lrrrrrrrr}\text { RTE1R } & 2.018 & .538 & 14.056 & 1 & .000 * & 7.520 & 2.619 & 21.592 \\ \text { RTE4R } & 1.280 & .479 & 7.159 & 1 & .007 * & 3.598 & 1.408 & 9.191 \\ \text { RTE5R } & 1.055 & .508 & 4.311 & 1 & .038 * & 2.873 & 1.061 & 7.779 \\ \text { Constant }-10.190 & 2.083 & 23.933 & 1 & .000 & .000 & & \end{array}$

${ }^{*} p<.05$

Table 11

Classification Table for step 5

Predicted

Observed

Fail

Pass

Total

$\%$ correct

\begin{tabular}{lrrrr}
\hline Fail & 17 & 8 & 25 & $68.0^{\text {a }}$ \\
Pass & 7 & 143 & 150 & $95.3^{b}$ \\
\hline Total & 24 & 151 & 175 & \\
\hline
\end{tabular}

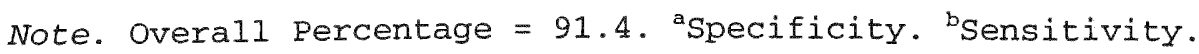


Research Question \#3

To what degree does the noncognitive variable, selfefficacy, predict national Registry exam success for graduates from Florida community college radiography programs?

Self-efficacy scores were obtained for students during the beginning of the second academic year of the program. There was a negative correlation with the national Registry exam results $(-0.059)$ as indicated in Table 2 . Logistic regression was used to determine the probability of a graduate passing the national Registry exam on the firstattempt using the self-efficacy score as the independent variable. As presented earlier, the results of the logistic regressions for the self-efficacy independent variable using either method were not significant. The independent variable, self-efficacy, was not found to be predictive of success on the national Registry exam for this sample (Tables 3 and 8 ).

Research Question \#4

To what degree does the noncognitive variable, social support, predict national Registry exam success for graduates from Florida community college radiography programs? 
Social support scores were obtained for students during the beginning of the second academic year of the program. There was no significant correlation with the national Registry exam results $(r=0.043)$ as indicated in Table 4. Logistic regression was used to determine the probability of a student passing the national Registry exam on the first-attempt using the independent variable social support. The results of the logistic regressions for the social support independent variable are shown in Tables 3 and 8. As presented earlier, the results of the logistic regressions for the social support independent variable using either method were not significant. The independent variable, social support, was not found to be predictive of success on the national Registry exam for this sample (Tables 3 and 8 ).

The results of the independent t-tests conducted to determine group differences between performance on the national Registry and the four significant predictor variables indicated a significant difference for all four variables; end of program GPA, RTE 1418, RTE 1613, and RTE 2385. There was a significant difference between the two groups in their performance on the national Registry Exam for the end of program GPA variable, 
$t(173)=-8.66, p<.05(t$ score is negative because it compared FAIL to PASS, alphabetically $F$ comes before P). The graduates in the pass group had a statistically significant higher end of program GPA than the fail group (3.60 Mean PASS VS. $\left.3.04_{\text {Mean FAIL }}\right)$.

The two groups also differed in their means for the three significant course predictor variables. For RTE 1418 , those who passed had a statistically significant higher average grade $\left(3.29_{\text {mean }}\right.$ PASS VS. $2.28_{\text {Mean FAIL }}$ ) for the course than those who failed, $t(173)=-7.37, \mathrm{p}<.05$. For RTE 1613, those who passed also had a statistically significant higher average grade (3.34 mean PASS VS. $2.40_{\text {Mean FAIL }}$ ) for the course, $t(173)=-6.48, p<.05$. For RTE 2385, those who passed also had a statistically significant higher average grade $\left(3.27_{\text {mean PASS }}\right.$ vs. $\left.2.40_{\text {Mean FAIL }}\right)$ for the course, $t(173)=-5.89, p<.05$.

To cross validate the results of the logistic regression stepwise method, a random sample of $50 \%$ of the cases were selected and another logistic regression was done to see if the variables entered into the logistic regression would correctly predict passing the exam. Overall, the model significantly predicted success pass rates, $F(4,88)=16.31, p<.05$. 


\section{Summary}

This study examined the predictive merits of cognitive and noncognitive variables on 175 recent graduates from community college radiography programs throughout the state of Florida on the national Registry exam.

The findings of the study by each research question are summarized below. The four research questions were tested with two different methods of logistic regression analysis.

To what degree do the cognitive variables, end of first year GPA and end of program GPA, predict national Registry exam success for graduates from Florida community college radiography programs? The end of the program GPA was found to be a significant predictor in the final models. According to the findings, as the end of program GPA increases, the likelihood of passing the national Registry exam increases.

To what degree do the cognitive variables, final grades in the program courses RTE 1418 Radiographic Exposures, RTE 1503 Radiographic Procedures I, RTE 1513 Radiographic Procedures II, RTE 1613 Radiologic Physics, and RTE 2385 Radiation Safety \& Protection, predict national Registry exam success for graduates from Florida 
community college radiography programs? RTE 1418, 1613, and 2385 were found to be significant predictors.

To what degree does the noncognitive variable, selfefficacy, predict national Registry exam success for graduates from Florida community college radiography programs? Self-efficacy was not a significant predictor.

To what degree does the noncognitive variable, social support, predict national Registry exam success for graduates from Florida community college radiography programs? Social support was not a significant predictor. Two final models were found to be significant for this sample. First, end of year GPA (GPA2) was predictive of success on the national Registry exam. Second, three of the curricular courses, RTE 1418, 1613, and 2385, were found to be predictive of success on the national Registry exam. There was a significant difference between the pass and fail groups for all four significant predictor variables.

Chapter 5 presents the study summary, a discussion of the findings, conclusions based on the findings, limitations of the study, recommendations for practice, and recommendations for further research. 


\section{CHAPTER V}

\section{SUMMARY AND DISCUSSION}

This chapter of the dissertation includes a summary of the study, discussion of the findings, and its limitations. Also included in this chapter are the implications for practice and recommendations for further research.

\section{Summary of the study}

This study examined the predictive merits of grade point averages (GPAs) at two progression points in the radiography curriculum and final grades in five specific program courses on the national Registry exam for 2008 graduates of Florida community college radiography programs. In addition, students' perceived self-efficacy and social support were measured to predict success on the national Registry exam for 2008 graduates of Florida community college radiography programs.

A researcher developed questionnaire was administered to 209 second-year students enrolled in community college radiography programs throughout the state of Florida who were expected to graduate and take the national Registry exam prior to the end of september 2008 to collect data on their perceived self-efficacy and faculty social support. Students who completed the first questionnaire were 
surveyed approximately 1 month after completing the program using the self-report method to obtain their radiography curriculum course grades and results on their first-attempt on the national Registry exam (pass or fail). A total of 175 graduates returned the second questionnaire and became the sample for the study.

Four research questions guided the study and were tested using the enter and backward stepwise methods of logistic regression analysis. The research questions were: (a) To what degree do the cognitive variables, end of first year GPA and end of program GPA, predict national Registry exam success for graduates from Florida community college radiography programs, (b) To what degree do the cognitive variables, final grades in the program courses RTE 1418 Radiographic Exposures, RTE 1503 Radiographic Procedures I, RTE 1513 Radiographic Procedures II, RTE 1613 Radiologic Physics, and RTE 2385 Radiation Safety \& Protection, predict national Registry exam success for graduates from Florida community college radiography programs, (c) To what degree does the noncognitive variable, self-efficacy, predict national Registry exam success for graduates from Florida community college radiography programs, and (d) To what degree does the noncognitive variable, social support, 
predict national Registry exam success for graduates from Florida community college radiography programs? Each variable's ability to predict success (pass) was examined independently of one another.

Study findings indicated that two models were produced that predicted success on the national Registry exam. In the first model, the end of program GPA was significant in predicting success on the national Registry exam. In the second model, RTE 1418 Radiographic Exposures, RTE 1613 Radiologic Physics, and RTE 2385 Radiation Safety \& Protection were significant in predicting success on the national Registry exam. The two noncognitive variables included in the study, self-efficacy and social support, were not correlated with success on the national Registry exam and were not significant as predictors.

Discussion of the Findings

Pearson Product-Moment Correlation analysis was computed to measure the strength of the association between the dependent variable and all of the independent variables. Statistically significant correlations were found between all of the independent variables except selfefficacy and social support. All of the independent variables, except self-efficacy and social support, 
correlated with success on the national Registry exam $(p<.01)$. The correlation between self-efficacy and social support was significant $(p<.05)$.

The independent variables were entered into a logistic regression equation using the enter and backward stepwise methods to determine the probability that the event, passing the national Registry exam on the first attempt, will happen, and to evaluate the relationship between the dependent variable and the independent variable. In the first logistic regression, just the end of the program GPA was statistically significant, indicating that the model was able to predict which graduates would pass the national Registry exam on the first-attempt. This model explained between $25.6 \%$ (Cox and Snell $R$ square) and $45.8 \%$ (Nagelkerke $R$ square) of the variance in passing the national Registry exam on the first-attempt, and correctly classified $89.7 \%$ of graduates. When using the end of the program GPA independent variable, it was more difficult to predict those who failed than those students who passed the national Registry exam. The end of the first year GPA was not significant in the model, therefore it is not a predictor of success on the national Registry exam for this sample. 
The results of this study are comparable to some of the previous studies that have included GPA as a predictor variable in other educational programs (Lamm \& McDaniel, 2000; Landry, 1997; Stuenkel, 2002; Yates, 2007). Results of this study indicate that it is possible to predict success or failure on the national Registry exam for radiography program graduates using the end of program GPA. According to the model produced in this study using the enter method, as the end of the program GPA increases one unit, for example from 2.0 to 3.0 , a student is 27.7 times more likely to pass than fail the national Registry exam on the first attempt. The backward stepwise model, however indicated that a student is 102.6 times more likely to pass than fail the national Registry exam on the first attempt. Based on these results, the odds ratio to pass the national Registry exam is higher using the backward stepwise model. The model produced in this study could be more useful to faculty and students by using a more realistic unit for the GPA. According to the model produced using the enter method, as the end of the program GPA increases by 0.1 , for example 2.5 to 2.6 , a student is 1.39 times more likely to pass than fail the national Registry exam on the first attempt. The backward stepwise model, however indicated 
that a student is 1.59 times more likely to pass than fail the national Registry exam on the first attempt. If the GPA unit of measure was 0.5 , for example 2.5 to 3.0 , a student is 5.27 times more likely to pass than fail the national Registry exam on the first attempt using the enter method model. This student would be 10.13 times more likely to pass than fail the national Registry exam on the first attempt using the backward method model. Therefore the higher the end of the program GPA, the more likely students will pass the national Registry exam on the first attempt. Based on the study results, graduates who are at potential risk, those predicted to fail, should be appropriately advised to complete some form of intervention, such as tutoring, completing a Registry review course, or dedicating additional time in preparation for the national Registry exam. Since both logistic regression models for the end of program GPA had a correct prediction rate of $96.7-97.3 \%$ using this variable to determine success on the national Registry exam, the progression point can safely be used by faculty to advise students on their likelihood of passing the national Registry exam on the first-attempt. This model had a 36$44 \%$ success rate on predicting students who failed the 
national Registry exam so it should be used cautiously when advising students about their likelihood of failing the national Registry exam. A false negative could be harmful to the student's self-confidence. It should not be used in isolation as a predictor of failing the national Registry exam, based on its poor prediction rate for failure.

The results of using an in-program GPA (end of first year) to predict success on the national Registry exam did not correlate with other studies completed in the past to predict success on a licensing exam (Beeson \& Kissling, 2001; Stright, 1993). Even though these previous studies did not include community college radiography graduates, using an in-program GPA at the end of the first year in the program should be considered by faculty as a variable that may predict in-program student success on the national Registry exam. Since the end of the first year GPA ultimately affects the end of the program GPA and may very well be calculated using the final grades from these courses that were found to be significant predictors of success (RTE 1418, 1613, 2385), the end of first year GPA should be monitored. According to the results of this study, using the GPA at the second tested progression point, end of the program, would be helpful to the faculty 
and students as an indicator of success on the national Registry exam.

The results of this study indicate that using a GPA from multiple institutions is an effective predictor of success for all students included in the sample. The literature differs on whether or not a GPA from different institutions can be used to fairly compare students (Astin, 2001; Young, 1995). For this setting and sample, using GPAs from different colleges $(N=19)$, based on different grading criteria and scales, can successfully predict academic success on the national Registry exam. Even though faculty with varied teaching styles throughout the state of Florida used different instructional methodology to present and measure the standard radiography curriculum content, the outcomes were the same in all of the programs.

The logistic regression analysis that included all five selected curricular courses using the backward stepwise method revealed that the model initially was a good fit $(p<.05)$. In the final model where all five courses were entered together, only three (RTE 1418 Radiographic Exposures, RTE 1613 Radiologic Physics, and RTE 2385 Radiation Safety \& Protection) of them were left, all of which were significant at $p<.05$. 
These results are comparable to some of the previous studies that included final grades for in-program courses as predictor variables using students from disciplines other than radiography (Beeman \& Waterhouse, 2001; Collins, 2002; Hill-Besinque, 2000; Percoco, 2002; Yates, 2007). All of these studies found specific required curricular courses that predicted success on a standardized licensing examination for a health profession.

Results of this study indicate that it is possible to predict success or failure on the national Registry exam for radiography program graduates when using in-program theory courses together, specifically, RTE 1418, RTE 1613, and RTE 2385. According to the model produced using the enter method, as the final course grade for RTE 1418 Radiographic Exposures (RTE1R) increases one letter grade, for example from 2.0 to 3.0 , a student is 9.1 times more likely to pass than fail the national Registry exam on the first attempt.

The backward stepwise model however indicated that that same student is only 7.5 times more likely to pass than fail the national Registry exam on the first attempt. For RTE 1613 Radiologic Physics (RTE4R), an increase in one letter grade increases the likelihood of passing 3.4 times 
using the enter method and 3.6 times using the backward stepwise model. For RTE 2385 Radiation Safety \& Protection (RTE5R) an increase in one letter grade increases the likelihood of passing 2.9 times using the enter method and 2.8 times using the backward stepwise model. Thus students who pass these courses with a " $\mathrm{C}$ " should be considered atrisk and advised to seek some form of intervention prior to taking the national Registry exam.

The logistic regression analysis for self-efficacy did not result in a significant finding. In the Pearson Product-Moment Correlation analysis, self-efficacy was not significant either. For this sample, students' perceived self-efficacy was not predictive of their success on the national Registry exam. These results do not support the findings of previous studies that included self-efficacy as a predictor variable (Chemers et al., 2001; House, 1993b, 2001; Solberg \& Villareal, 1997; Wilhite, 1990). With different measures of self-efficacy, samples, settings, and dependent variables, self-efficacy was found to be a significant predictor in these studies. Like the current study, these studies all measured self-efficacy based on students' perception in the present, but focusing on an outcome that would occur in the future. House (2001) 
measured self-efficacy prior to the start of the academic year and collected course grades at the end of the next three consecutive semesters. Chemers et al. (2001) measured self-efficacy at the end of the first quarter and found it to be related to academic performance at the end of the academic year.

Neither the Pearson Product-Moment Correlation analysis nor the logistic regression analysis for social support resulted in a significant finding. In this study, students' perceived social support was not predictive of their success on the national Registry exam. The results of this study do not support the findings of previous studies that included social support as a predictor variable (Coffman \& Gilligan, 2002; Hardre \& Reeve, 2003; LeGault et al., 2006; Reeve, 2002). With different measures of social support, samples, settings, and dependent variables, social support was found to be a significant predictor in all of these studies.

Perhaps the point in time when students' perceived social support was measured for the current study could have negatively affected the results. The studies by Carney-Crompton and Tan (2002), Hardre and Reeve (2003), and LeGault et al. (2006) all collected data on the 
independent variables and compared them to the dependent variable of GPA that was already in existence. Thus there was no lapse in time between when the variables were measured so a change in student perception could not occur. The study by Coffman and Gilligan (2002) measured the independent and dependent variables right after the other, which once again left no time for the independent variable to change. The procedure of the present study differed from all of these studies by measuring students' social support two semesters prior to taking the national Registry exam so perhaps the students' experiences or the time between the measurement of the two variables affected the results.

Both logistic regression analyses in this study included independent variables from the cognitive and noncognitive categories but produced significant models that only included cognitive variables. These results did not support the findings of previous studies that included variables from both cognitive and noncognitive categories (Dell \& Valine, 1990; Sayles, Shelton, \& Powel1, 2003; Stuenkel, 2002). Other studies found significant variables from both categories. Perhaps the current sample and selected variables differed from these past studies enough to produce different results. 
The observed proportion of students who passed the national Registry exam exceeded the expected proportion by chance in the sample. The results could be attributed to the academic preparation received in the curriculum since three courses and the end of program GPA were significant predictors of success on the national Registry exam. Other factors that may have contributed to exceeding the expected proportion could be the amount of time spent preparing for the national Registry exam outside of the classroom or attending a review course. These variables were not included in the current study.

Data files of the graduates who were not successful on the national Registry exam revealed two common factors that could have predicted their failure. These graduates in the current study demonstrated lower end of program GPAs and final course grades for all three significant predictor courses than the cohort who passed the national Registry exam. Since the lower course grades are reflected in the lower end of program GPAs, these three predictor courses are key to predicting success on the national Registry exam.

Perhaps some other unmeasured variable or variables had an effect on the graduates who failed the national 
Registry exam. With all the variables included in the study being equal, negative situational variables in the lives of those who failed may have been strong enough to override their ability to pass the national Registry exam. Extraneous factors such as a personal/family tragedy, general health, sudden conflict, a minor automobile accident the day of the exam, or financial crisis could have entered into the model.

Situational variables of varying degrees of severity often arise unexpectedly in the lives of students. For the students who failed the national Registry exam, these variables may have counteracted the mediating effect of the students' self-efficacy, social support, and previous academic achievement. Under normal circumstances, this cohort probably would have been successful on the national Registry exam.

\section{Limitations of the Study}

Results are reported for only those individuals who completed both data collection forms. The participants self-reported data and no attempt was made to verify the submitted data with the corresponding transcript. National Registry exam results are reported to the individual while the program officials only receive anonymous results. 
Therefore it is not possible to verify which graduates actually passed or failed on the first-attempt.

Conclusions

Within the limitations of this study, the following conclusions were reached:

1. The findings of this study agree with similar studies that the academic measure (GPA) taken at the end of the program is the best predictor of success on a standardized Registry or licensing exam first attempt.

2. Only the final grade for three of the five selected curricular courses proved to be predictors of success on the national Registry exam first attempt in the overall model using only courses.

3. Students' level of perceived self-efficacy proved not to be correlated with or be a predictor of success on the national Registry exam first attempt.

4. Students' level of perceived social support from the program faculty proved not to be correlated with or be a predictor of success on the national Registry exam first attempt.

5. For the sample used in this study, the best model to predict success on the national Registry exam included the end of the program GPA and the final grades for 
RTE 1418 Radiographic Exposures, RTE 1613 Radiologic Physics, and RTE 2385 Radiation Safety \& Protection. Implications for Practice

Under the constraints of the community college philosophy of an open-door policy, even though most Health Science programs adopt strict admission criteria and follow a specific selection process due to limited access to the programs, all students should be admitted on the basis that they will more than likely be successful in the program, on the national Registry exam, and in their professional career.

1. The final grades for RTE 1418 Radiographic Exposures, RTE 1613 Radiologic Physics, and RTE 2385 Radiation Safety \& Protection, or courses with similar competencies, should be considered as early warning signs to the faculty and students. Interventions should be encouraged for students who earn a final grade of a " $\mathrm{C}$ " in these courses to avoid the possibility of failing the national Registry exam. The other two courses that were not significant as predictors should be reviewed and revised to more closely match the national Registry exam blueprint. 
2. The GPA at the end of the program should be reviewed by both faculty and student prior to the graduate taking the national Registry exam. The GPA could predict the results on the national Registry exam. Students with a GPA further away from a 4.0 should be advised to spend additional time preparing for the national Registry exam before actually attempting to take it. For students in the present study, the curriculum appears to be a good fit in preparing them to pass the national Registry exam.

3. Although the two selected noncognitive variables for this study were not significant predictors of success on the national Registry exam first-attempt for this sample, they should not be discarded as having no effect on the graduates. Previously cited studies have indicated the predictability of these two noncognitive variables to predict student academic success.

\section{Recommendations for Further Research}

A major issue in higher education is documenting student learning. Institutions of higher education use information about student learning to improve instruction and document student learning to accrediting agencies and various funding sources (Flowers et al., 2001; Stone \& 
Friedman, 2002). One tool used by researchers to provide evidence that students learn in college is standardized tests.

Despite the importance of standardized tests, researchers have identified sources of error that lower students' test scores, such as content sampling, insufficient time to complete the test, low motivation, and student's health condition on test day, which ultimately misrepresent what students actually learned (Anastasi \& Urbina, 1997; Gronlund, 2006; Reynolds et al., 2006). Test performance has been recognized as a function of knowledge and motivation, therefore such factors as low student motivation or test conditions can challenge whether data collected on standardized tests are a valid measure of student achievement (Cole, 2007; Eklof, 2006; Wainer, 1993).

The demand for more accountability for student achievement in the classroom has increased. It has held center stage over the past decade or more for those who have shaped education policies at both levels of government. Mandated accountability, through state and federal legislation as well as health science accrediting agencies, is intended to improve the quality of education 
for all students at all levels of education. Accountability is a shared responsibility between educators, students, administrators, and educational researchers. As various accountability systems to improve the quality of education emerge, they need to be based on past research evidence. Based on the results of this study and its limitations, the following recommendations for further research are offered below. Some of these recommendations could increase the generalizability, predictability or validity of the results, while others address perceived gaps in the literature on predicting success on standardized exams.

1. This study should be replicated using a larger and more diverse sample by including more than one state to facilitate generalization to radiography programs at large.

2. Consider other curricular courses to determine better predictors of national Registry exam success. Research has identified courses such as anatomy and physiology to be a predictor of success on other certification exams.

3. Collect data on the two noncognitive variables (selfefficacy and social support) at the end of the 
curriculum just prior to taking the national Registry exam to determine their predictive merit on the national Registry exam. Perhaps taking measures at different progression points during the curriculum would produce different results.

4. Include other noncognitive variables to determine their predictive merit on the national Registry exam, such as motivation, positive self-concept, preference for long-term goals, realistic self-appraisal, or even sources of social support other than faculty.

5. Consider nonacademic variables, such as participation in a national Registry exam prep course, the amount of independent time dedicated to preparing for the national Registry exam, or the length of time between program completion and taking the national Registry exam that could affect the first-attempt results on the national Registry exam.

6. Consider program characteristics such as faculty credentials, program attrition rate, class size, entrance requirements, and progression policies as predictors of success on the national Registry exam. 7. Collect data on student readiness to take the national Registry exam at the end of the program and how long 
after the end of the program they take the national Registry exam. These two variables should be compared with the national Registry exam results.

8. Periodically repeat this study when the national Registry exam content changes or to validate curriculum changes.

This study was conducted to fill a gap in the literature of studies that predict graduation and success on the national Registry exam for community college radiography students. Predictors of academic success have been identified to empower radiography educators to increase the likelihood of success on the national Registry exam. Radiography faculty can use the identified courses and end of program GPA to identify which students will require supplementary aid prior to taking the national Registry exam. Appropriate intervention could reduce the number of graduates who fail the national Registry exam on their first attempt, thus improving program pass rates and increasing the probability of meeting or exceeding the Joint Review Committee on Education in Radiologic Technology (JRCERT) pass-rate outcomes benchmark. The results of this study may hopefully improve radiography program outcomes. 


\section{REFERENCES}

Alfassi, M. (2003). Promoting the will and skill of students at academic risk: An evaluation of an instructional design geared to foster achievement, self-efficacy and motivation. Journal of Instructional Psychology, 30(1), 28-40.

American registry of radiologic technologists:

Psychometrics annual report of exams 2007. Retrieved on February 20, 2008, from American Registry of Radiologic Technologists Web site:

http: //arrt.org/psychometrics/annualreportofexams 2007 . pdf

Ames, C. \& Ames, R. (1984). Systems of student and teacher motivation: Toward a qualitative definition. Journal of Educational Psychology, 76(4). 535-556.

Anastasi, A., \& Urbina, S. (1997). Psychological testing (7th ed.). Upper Saddle River, NJ: Prentice Hall.

Ancis, J. R., \& Sedlacek, W. E. (1997). Predicting the academic achievement of female students using the SAT and noncognitive variables. College and University, $72(3), 1-8$.

Andrews, A. W., Johansson, C., Chinworth, S. A., \& Akroydt, D. (2006). Cognitive, collegiate, and demographic predictors of attrition in professional physical therapist education. Journal of Physical Therapy Education, 20(1), 14-21.

Arbona, C., \& Novy, D. M. (1990). Noncognitive dimensions as predictors of college success among blacks, mexican-american, and white students. Journal of College Student Development, 31(5), 415-422.

Ashley, J., \& O'Neil, J. (1991). The effectiveness of an intervention to promote successful performance on NCLEX-RN for baccalaureate students. Journal of Nursing Education, 30(8), 360-366.

Astin, A. W. (1974). Measuring the Outcomes of Higher Education. New Directions for Institutional Research, $1(1), 23-46$. 
Astin, A. W. (1975). Preventing student from dropping out. San Francisco: Jossey-Bass.

Astin, A. W. (1991). The Changing American College Student: Implications for Educational Policy and Practice. Higher Education, 22(2), 129-43.

Astin, A. W. (2001). What matters in college? San Francisco: Jossey-Bass.

Ballinger, P. W. (1976). Predicting clinical performance of radiologic technology students. Radiologic Technology, $48(6), 364-371$.

Bandura, A. (1977). Self-efficacy: Toward a unifying theory of behavioral change. Psychological Review, 84(2), 191-215.

Bandura, A. (1982). Self-efficacy mechanism in human agency. American Psychologist, 37, 122-147.

Bandura, A. (1986). Social foundations of thought and action: A social cognitive theory. Englewood Cliff, NJ : Prentice-Hall.

Bandura, A. (1997). Self-efficacy: The exercise of control. New York: W. H. Freeman and Company.

Barnes, V., Potter, E. H., III, \& Friedler, F. E. (1983). Effect of interpersonal stress on the prediction of academic performance. Jounnal of Applied Psychology, $68(4), 686-697$.

Barrera, Jr., M., Sandler, I. N., \& Ramsay, T. B. (1981). Preliminary development of a scale of social support: Studies on college students. American Journal of Community Psychology, 9(4), 435-447.

Barry, P. O. (1984). An analysis of selected admission criteria as predictors of success on the American registry of radiologic technologists (Doctoral dissertation, Kansas State University, 1983). Dissertation Abstracts International, 44(12), 3712-3797. 
Bauchmoyer, S. M., Carr, M. P., Clutter, J. E., \& Hoberty, P. D. (2004). Predicting academic and national board dental hygiene examination performance based on academic factors. The Journal of Dental Hygiene, $78(1), 39-45$.

Beeman, P. B., \& Waterhouse, J. K. (2001). NCLEX-RN performance: Predicting success on the computerized examination. Journal of Professional Nursing, 17(4), $158-165$.

Beeson, S. A., \& Kissling, G. (2001). Predicting success for baccalaureate graduates on the NCLEX-RN. Journal of Professional Nursing, 17(3), 121-127.

Benard, B. (2004). Resiliency: What we have learned. San Francisco: Wested.

Boyer, S. P., \& Sedlacek, W. E. (1988). Noncognitive predictors of academic success for international students: A longitudinal study. Journal of College Student Development, 29(3), 218-223.

Byrd, G., Garza, C., \& Niesswiadomy, R. (1999). Predictors of successful completion of a baccalaureate nursing program. Nurse Educator, 24(6), 33-37.

Campbell, A. R., \& Dickson, C. J. (1996). Predicting student success: A 10-year review using integrative review and meta-analysis. Journal of Professional Nursing, 12(1), 47-59.

Caplan, G. (1974). Support Systems and community mental health: Lectures on concept development. New York: Behavioral Publications.

Carney-Crompton, S., \& Tan, J. (2002). Support systems, psychological functioning, and academic performance of nontraditional female students. Adult Education Quarterly, 52(2), 140-154.

Cassel, J. (1974a). An epidemiological perspective of psychosocial factors in disease etiology. American Journal of Public Health, 64(11), 1040-1043. 
Cassel, J. (1974b). Psychosocial processes and "stress": Theoretical formulations. International Journal of Health Services, 4(3), 471-482.

Chemers, M. M., Hu, L., \& Garcia, B. F. (2001). Academic self-efficacy and first-year college students performance and adjustment. Journal of Educational Psychology, 93(1), 55-64.

Cobb, S. (1976). Social support as a moderator of life stress. Psychosomatic Medicine, 38(5), 300-314.

Coffman, D. L., \& Gilligan, T. D. (2002-2003). Social support, stress, and self-efficacy: Effects on students' satisfaction. College Student Retention, $4(1), 53-66$.

Cole, James S. (2008) Motivation to do well on low-stakes tests. (Doctoral Dissertation, University of Missouri - Columbia, 2007). Dissertations Abstracts International, 69, 06.

Collins, P. (2002). Predicting a passing outcome on the national council licensure examination for registered nurses by associate degree graduates. Dissertation Abstracts Internationa1, 54(01), 142B. (UMI No. 3077374)

Davidson, M. N., \& Foster-Johnson, L. (2002). Mentoring in the preparation of graduate researchers of color. Review of Educational Research, 71(4), 549-574.

DeAngelis, S. (2003). Noncognitive predictors of academic performance: Going beyond the traditional measures. Journal of Allied Health, 32(1), 52-57.

DeBerard, M. S., Spielman, G. I., \& Julka, D. L. (2004). Predictors of academic achievement and retention among college freshmen: A longitudinal study. College Student Journal, 38(1), 66-80.

Dell, M. S., \& Valine, W. J. (1990). Explaining the difference in NCLEX-RN scores with certain cognitive and non-cognitive factors for new baccalaureate nurse graduates. Journal of Nursing Education, 29(4), 158-162. 
Dentlinger, N. C. (2003). Academic self-efficacy, prior academic success, demographic variables, and academic success in first semester associate degree nursing coursework. Dissertation Abstracts International, $64(06), 1948 \mathrm{~A}$. (UMI No. 3094039)

Dormire, S. L., Strauss, S. S., \& Clarke, B. A. (1989). Social support and adaptation to the parent role in first-time adolescent mothers. Journal of Obstetrics, Gynecologic, and Neonatal Nursing, 18(4), 327-336.

Duffy, M. E. (1989). The primary support received by recently divorced mothers. Western Journal of Nursing Research, 11(6), 676-693.

Dunkley, D. M., Blankstein, K. R., Halsall, J., Williams, M., \& Winkworth, G. (2000). The relation between perfectionism and distress: Hassles, coping, and perceived social support as mediators and moderators. Journal of Counseling Psychology, 47(4), 437-453.

Dwyer, A. L., \& Cummings, A. L. (2001). Stress, selfefficacy, social support, and coping strategies in college students. Canadian Journal of Counseling, $35(3), 208-220$.

Eccles, J. S., \& Midgley, C. (1989). Stage-environment fit: Developmentally appropriate classrooms for young adolescents. In C. Ames \& R. Ames (Eds.), Research on motivation in education: Vol. 3. Goals and cognitions (pp. 139-186). New York: Academic Press.

Eklof, H. (2006). Development and validation of scores from an instrument measuring test-taking motivation. Educational and Psychological Measurement, $66(4), 643-656$.

Elliott, T. R., Herrick, S. M., \& Witty, T. E. (1992). Problem-solving appraisal and the effects of social support among college students and persons with physical disabilities. Journal of Counseling Psychology, 39(2), 219-226.

Fleming, J. (1984). Blacks in college: A comparative study of students' success in Black and White institutions. San Francisco: Jossey-Bass. 
Flowers, L., Osterlind, S. J., Pascarella, E. T., \& Pierson, C. T. (2001). How much do students learn in college? Cross-sectional estimates using College BASE. Journal of Higher Education, 72(5), 565-583.

Fowles, E. R. (1992). Predictors of success on the NCLEX-RN and within the nursing curriculum: Implications for early intervention. Journal of Nursing Education, $31(2), 53-57$.

Foxall, M. J., Barron, C. R., Von Dollen, K., Shull, K. A., \& Jones, P. A. (1994). Low-vision elders: Living arrangements, loneliness, and social support. Journal of Gerontological Nursing, 20(8), 6-14.

Frierson, J., H. T., Malone, B., \& Shelton, P. (1993). Enhancing NCLEX-RN performance: Assessing a threepronged intervention approach. Journal of Nursing Education, 32(5), 222-224.

Fries-Britt, S. (2000). Identity development of highability Black collegians. New directions for teaching and learning, 2000(82), 55-65.

Furrer, C., \& Skinner, E. (2003). Sense of relatedness as a factor in children's academic engagement and performance. Journal of Educational Psychology, $95(1), 148-162$.

Garson, G. D. (2008). Stepwise logistic regression. Retrieved on August 8, 2008, from http: / / faculty.chass.ncsu.edu/garson/PA765/logistic.ht m\#stepwise

General perceived self-efficacy scale. Retrieved July 10, 2007 from the General Perceived Self-efficacy Scale website: http://web.fuberlin.de/gesund/publicat/ehps_cd/health/engscal.htm

Gore, P. A., Jr. (2006). Academic self-efficacy as a predictor of college outcomes: Two incremental validity studies. Journal of Career Assessment, 14(1), 92-115.

Gornlund, N. E. (2006). Assessment of student achievement (6th ed.). Boston: Allyn \& Bacon. 
Hardre, P. L., \& Reeve, J. (2003). A motivational model of rural students' intentions to persist in, versus drop out of, high school. Journal of Educational Psychology, 95(2), 347-356.

Heupe1, C. (1994). A model for intervention and predicting success on the national council licensure examination for registered nurses. Journal of Professional Nursing, 10(1), 57-60.

Hill-Bisenque, K. (2000). Predictors of success rate in the California state board of pharmacy licensure examination. American Journal of Pharmaceutical Education, 64(1), 50-53.

Horns, P. N., O'Sullivan, P., \& Goodman, R. (1991). The use of progressive indicators as predictors of NCLEX-RN success and performance of BSN graduates. Journal of Nursing Education, 30(1), 9-14.

Hosmer, D. W., \& Lemeshow, S. (2000). Applied logistic regression (2nd ed.). New York: Wiley.

House, J. D. (1993a). Achievement expectancies as predictors of academic performance. International Journal of Instructional Media, 20(3), 213-223.

House, J. D. (1993b). Cognitive-motivational predictors of science achievement. International Journal of Instructional Media, 20(2), 155-162.

House, J. D. (1995a). Noncognitive predictors of achievement in introductory college mathematics. Journal of College Student Development, 36(2), 171-181.

House, J. D. (1995b). Noncognitive predictors of achievement in introductory college chemistry. Research in Higher Education, 36(4), 473-490.

House, J. D. (2000). Relationships between self-beliefs, academic background, and achievement of undergraduate students in health science majors. International Journal of Instructional Media, 27(4), 427-438. 
House, J. D. (2001). Cognitive-motivational predictors of science achievement undergraduate students in health sciences majors. International Journal of Instructional Media, 28(2), 181-190.

House, J. D., Keeley, E. J., \& Hurst, R. S. (1996). Relationships between learner attitudes, prior achievement, and performance in a general education course: A multi-institutional study. International Journal of Instructional Media, 23(3), 257-271.

House, J. D., \& Prion, S. K. (1998). Student attitudes and academic background as predictors of achievement in college english. International Journal of Instructional Media, 25(1), 29-42.

Howell, D. C. (2007). Statistical Methods for Psychology (6th ed.). United States: Thomson Wadsworth.

Hupcey, J. E. (1998) . Clarifying the social support theoryresearch linkage. Journal of Advanced Nursing, 27(6), 1231-1241.

Hyers, A. D., \& Zimmerman, A. (2002). Using segmentation modeling to predict graduation at a two-year technical college. Community College Review, 30(1), 1-26.

Jacobi, M. (1991). Mentoring and undergraduate academic success: A literature review. Review of Educational Research, 61(4), 505-532.

Jeffreys, M. R. (1998). Predicting nontraditional student retention and academic achievement. Nurse Educator, $23(1), 42-48$.

Jenks, J., Selekman, J., Bross, T., \& Paquet, M. (1989). Success in NCLEX-RN: Identifying predictors and optimal timing for intervention. Journal of Nursing Education, 28(3), 112-118.

Johnson, I. H. (1996). Access and retention: Support programs for graduate and professional students. In I. $\mathrm{H}$. Johnson \& A. J. Ottens (Eds.), Leveling the playing field: Promoting academic success for students of color (pp. 4-12). San Francisco: Jossey-Bass. 
Jung, J. (1989). The relationship of daily hassles, social support, and coping to depression in Black and White students. Journal of General Psychology, 116(4), 407-417.

Kanoy, W. K., Wester, J., \& Lata, M. (1989). Predicting college success on freshmen using traditional cognitive, psychological measures. Journal of Research and Development in Education, 22(3), 133-140.

Kilpatrick-Demaray, M., \& Kerres-Malecki, C. (2003).

Importance ratings of socially supportive behaviors by children and adolescents. School Psychology Review, $32(1), 108-131$.

Klomegah, R. Y. (2007). Predictors of academic performance of university students: An application of the goal efficacy model. College Student Journal, 41(2), $407-415$.

Krupa, K. C., Quick, M. M., \& Whitley, T. W. (1988). The effectiveness of nursing grades in predicting performance on the NCLEX-RN. Journal of Professional Nursing, 4(4), 294-298.

Kuh, G. D., Kinzie, J., Schuh, J. H., \& Whitt, E. J. (2005). Assessing conditions to enhance educational effectiveness: The inventory for student engagement and success. San Francisco: John Wiley \& Sons, Inc.

Lamm, G., \& McDaniel, A. M. (2000). Factors that predict success on the NCLEX-PN. Journal of Nursing Education, $39(7), 315-317$.

Landry, D. (1997). An investigation of selected variables to predict student performance on the national council licensure examination for registered nurses (NCLEX-RN) in one baccalaureate degree nursing program. Dissertation Abstracts International, 58(12), 4511A. (UMI No. 9819095)

Legault, L., Green-Demers, I., \& Pelletier, L. (2006). Why do high school students lack motivation in the classroom? Toward an understanding of academic amotivation and the role of social support. Journal of Educational Psychology, 98(3), 567-582. 
Lent, R. W., Brown, S. D., \& Larkin, K. C. (1984). Relation of self-efficacy expectations to academic achievement and persistence. Journal of Counseling Psychology, $31(3), 356-362$.

Likelihood-ratio test. (2008). Retrieved August 30, 2008, from Logistic Regression Web site:

http://userwww.sfsu. edu/ efc/classes/biol710/logistic/ logisticreg.htm

Lynch, D. J. (2006). Motivational factors, learning strategies and resource management as predictors of course grades. College Student Journal, 40(2), $423-428$.

McKinney, J., Small, S., O'Dell, N., \& Coonrod, B. A. (1988). Identification of predictors of success for the NCLEX-RN and students at risk for NCLEX-RN failure in a baccalaureate nursing program. Journal of Professional Nursing, 4(1), 55-59.

Menard, S. W. (2002). Applied logistic regression analysis (2nd ed.). Thousand Oaks, CA: Sage Publications.

Miller, P., McMahon, M. A., \& Garrett, M. J. (1989). A content analysis of life adjustments post infarction. Western Journal of Nursing Research, 11(5), 559-567.

Mills, A. C., Becker, A. M., Sampel, M. E., \& Pohlman, V. C. (1992). Success-failure on the national council licensure examination for registered nurses by nurse candidates from an accelerated baccalaureate nursing program. Journal of Professional Nursing, 8(6), 351-357.

Mills, A. C., Sampel, M. E., Pohlman, V. C., \& Becker, A. M. (1992). The odds for success on NCLEX-RN by nurse candidates from a four-year baccalaureate nursing program. Journal of Nursing Education, 31(9), 403-408.

Multon, K. D., Brown, S. D., \& Lent, R. W. (1991). Relation of self-efficacy beliefs to academic outcomes: A metaanalytic investigation. Journal of Counseling Pyschology, 38(1), 30-38. 
Nagelkerke, N. J. D., (1991). A note on a general definition of the coefficient of determination. Biometrika, 78(3), 691-692.

Nettles, M. (1990). Black, Hispanic, and White doctoral students: Before, during, and after enrolling in graduate school (Graduate Record Examinations No. MGE90-01). Princeton, N.J.: Educational Testing Service.

Oakes, D. L., Macharen, L. M., Gorie, C. T., \& Finstuen, K. (1999). Predicting success on the physician assistant national certification examination. Perspective on Physician Assistant Education, 10(2), 63-69.

Ostrow, E., Paul, S., Dark, V., \& Behram, J. (1986). Adjustment of women on campus: Effects of stressful life events, social support, and personal competencies. In S. E. Hobfoll (Ed.), Stress, social support, and women. (pp. 29-46). Washington, DC: Hemisphere.

Overall significance. (2008). Retrieved August 30, 2008, from University of Exeter Web site:

http://Www.people.ex.ac.uk/SEGLea/multvar2/disclogi.ht $\mathrm{ml}$

Pajares, F. (2001). Toward a positive psychology of academic motivation. The Journal of Educational Research, 95(1), 27-36.

Pajares F., \& Miller, M. D. (1994). Role of self-efficacy and self-concept beliefs in mathematical problem solving: A path analysis. Journal of Educational Psychology, 86(2) 193-203.

Pallant, J. (2007). SPSS survival manual (3rd ed.). England: MCGraw-Hill.

Patrick, H., Ryan, A. M., Alfred-Liro, C., Fredericks, J. A. , Hruda, L. Z., \& Eccles, J. S. (1999). Adolescents' commitment to developing talent: The role of peers in continuing motivation for sports and the arts. Journal of Youth and Adolescence, 28(6), 741-763. 
Payne, M. A., \& Duffy, M. A. (1986). An investigation of the predictability of NCLEX scores of BSN graduates using academic predictors. Journal of Professional Nursing, 2(5), 326-332.

Percoco, T. (2002). Variables predictive of program and NCLEX success for associate degree nursing students. Dissertation Abstracts International, 62(8), 3558B. (UMI No. 3023360)

Pintrich, P. R., \& DeGroot, E. V. (1990). Motivational and self-regulated learning components of classroom academic performance. Journal of Educational Psychology, 82(1), 33-40.

Pintrich, P. R., \& Schunk, D. H. (1995). Motivation in education: theory, research and applications. Englewood Cliffs, NJ: Prentice-Hall.

Pintrich, P. R., \& Schunk, D. H. (1996). Motivation in education: Theory research and applications. Upper Saddle River, NJ: Prentice-Hall.

Poorman, S. G., \& Martin, E. J. (1991). The role of nonacademic variables in passing the national council licensure examination. Journal of Professional Nursing, $7(1), 25-32$.

Pretty, G. M. H., \& McCarthy, M. (1991). Exploring psychological sense of community among women and men of the corporation. Journal of Community Psychology, 19(4), 351-361.

Procidano, M. E., \& Heller, K. (1983). Measures of perceived social support from friends and from family: Three validation studies. American Journal of Community Psychology, 11(1), 1-24.

Reeve, J. (2002). Self-determination theory applied to educational settings. In E. L. Deci \& R. M. Ryan (Eds.), Handbook of self-determination research (pp. 183-203). Rochester, NY: University of Rochester Press. 
Renninger, K. A., Hidi, S., \& Krapp, A. (1992). The role of interest in learning and development. Hillsdale, NJ: Erlbaum.

Reynolds, C. R., Livingston, R. B.. \& Willson, V. (2006). Measurement and assessment in education. Boston: Allyn $\&$ Bacon.

Robbins, S. B., Lauver, K., Le, H., Davis, D., Langley, R., \& Carlstrom, A. (2004). Do psychosocial and study skills factors predict college outcomes? A metaanalysis. Psychological Bulletin, 130(2), 261-288.

Rook, K. S., \& Dooley, D. (1985). Applying social support research: Theoretical problems and future directions. Journal of Social Issues, 41(1), 5-28.

Rosenholtz, S. J., \& Wilson, B. (1980). The effect of classroom structure on shared perceptions of ability. American Educational Research Journal, 17(1), 75-82.

Roye, T. (1997). Predictors of performance on the national council licensure examination for registered nurses by associate degree graduates. Dissertation Abstracts International, 58(9), 4143B. (UMI No. 9725696)

Ryan, T. P. (1997). Modern regression methods. New York: John Wiley \& Sons, Inc.

Sandow, P. L., Jones, A. C., Peek, C. W., Courts, F. J., \& Watson, R. E. (2002). Correlation of admission criteria with dental school performance and attrition. Journal of Dental Education, $66(3), 385-392$.

Sayles, S., Shelton, D., \& Powell, H. K. (2003). Predictors of success in nursing education. Association of Black Nursing Faculty Journal, 14(6), 116-120.

Schrader, W. B. (1977). Summary of law school validity studies, 1948-1975. Princeton, NJ: Law School Admission Council.

Schunk, D. H. (1981). Modeling and attributional effects on children's achievement: A self-efficacy analysis. Journal of Educational Psychology, 73(1), 93-105. 
Schunk, D. H., \& Hanson, A. R. (1985). Peer models: Influence on children's self-efficacy and achievement behaviors. Journal of Educational Psychology, 77(3), 313-322.

Schunk, D. H., Hanson, A. R., \& Cox, P. D. (1987). Peer model attributes and children's achievement behaviors. Journal of Educational Psychology, 79(1), 54-61.

Schwarzer, R. (Ed.). (1992). Self-efficacy: Thought control of action (1st ed.). Washington, DC: Hemisphere Publishing Corporation.

Sedlacek, W. E. (1989). Noncognitive indicators of student success. Journal of College Admissions, 125, 2-10.

Sedlacek, W. E. (2004). Beyond the big test. San Francisco: Jossey-Bass.

Shumaker, M. E. P., \& Brownell, A. (1984). Toward a theory of social support: Closing conceptual gaps. Journal of Social Issues, $40(4), 11-36$.

Shumaker, S. A., \& Hill, D. R. (1991). Gender differences in social support and physical health. Health Psychology, 10(2), 102-111.

Solberg, V. S., \& Villareal, P. (1997). Examination of self-efficacy, social support, and stress as predictors of psychological and physical distress among Hispanic college students. Hispanic Journal of Behavioral Sciences, 19(2), 182-201.

Stark, M. A., Feikema, B., \& Wyngarden, K. (2002). Empowering students for NCLEX success. Nurse Educator, $27(3), 103-105$.

Stewart, B. L. (1990). Perceived self-efficacy as a predictor of freshman grade point average for at-risk students and regular-admit students at the University of Pennsylvania. Dissertation Abstracts International, $51(05), 1525 \mathrm{~A}$. (UMI No. 9026655)

Stiewing, J. (2001). New standards. Radiologic Technology, $72(6), 598-604$. 
Stone, J., \& Friedman, S. (2002). A case study in the integration of assessment and general education: Lessons learned from a complex process. Assessment and Evaluation in Higher Education, 27(2), 199-221.

Stright, B. (1993). Predictors of performance of selected associate degree graduates on the national council licensure examination for registered nurses. Dissertation Abstracts International, 54(4), 1202B. (UMI No. 9324397)

Stuenkel, D. L. (2002). Using entrance criteria, achievement measures, and nursing assessment examinations to predict success on the national council licensure examination for registered nurses. Dissertation Abstracts International, 63(04), 1250A. (UMI No. 3049679)

Tabachnick, B.G., \& Fidell, L.S. (2007). Using multivariate statistics (5th ed.). Boston: Pearson Education.

The American Registry of Radiologic Technologists. (062808). Annual report: Results of the 2007 examinations in radiography, nuclear medicine technology, and radiation therapy. Retrieved June 28 , 2008, from

http://www.arrt.org/psychometrics/annualreportofexams2 $007 . p d f$

Ting, S. M. (1997). Estimating academic success in the 1st year of college for specially admitted white students: A model combining cognitive and psychosocial predictors. Journal of College Student Development, $38(4), 401-409$.

Ting, S. M., \& Robinson, T. L. (1998). First-year academic success: A prediction combining cognitive and psychosocial variables for Caucasian and African American students. Journal of College student Development, 39(6), 599-610.

Tinto, V. (1993). Leaving college: Rethinking the causes and cures of student attrition (2nd ed.). Chicago: The University of Chicago Press. 
Tollefson, N. (2000). Classroom applications of cognitive theories of motivation. Educational Psychology Review, $12(1), 63-83$.

Tracey, T. J., \& Sedlacek, W. E. (1984a). Noncognitive variables in predicting academic success by race. Measurement and Evaluation in Guidance, 16(4), $171-178$.

Tracey, T. J., \& Sedlacek, W. E. (1984b). Using ridge regressions with noncognitive variables by race in admissions. College and University, 59(4), 345-350.

Tracey, T. J., \& Sedlacek, W. E. (1985). The relationship of noncognitive variables to academic success: A longitudinal comparison by race. Journal of college Student Personne1, 26(5), 405-410.

Tracey, T. J., \& Sedlacek, W. E. (1989). Factor structure of the noncognitive questionnaire- revised across samples of Black and White college students. Educational and Psychological Measurement, 49(3), 637-648.

Undergraduate registration policies: Return of financial aid policy. (n.d.). Retrieved september 20, 2008, from Florida International University Web site: http://catalog.fiu.edu/index.php?id=5834\&section=acade micpolicies

Vaux, A. (1988). Social support: Theory, research, and intervention. New York: Praeger.

Veiel, H. O. F., \& Baumann, U. (1992). The many meanings of social support. In H. O. F. Veiel U. Baumann (eds.), The meaning and measurement of social support (pp. 19). New York: Hemisphere.

Wainer, H. (1993). Measurement problems. Journal of Educational Measurement, 30(1), 1-21.

Waterhouse, J. K., Bucher, L. \& \& Beeman, L. B. (1994). Predicting NCLEX-RN performance: Cross-validating an identified classification procedure. Journal of Professional Nursing, 10(4), 255-260. 
Weiner, B. (1974). Cognitive views of human motivation. New York: Academic Press.

Wentzel, K. R. (1997). Student motivation in middle school: The role of perceived pedagogical caring. Journal of Educational Psychology, 89(3), 411-419.

Wentzel, K. R. (1998). Social relationships and motivation in middle school: The role of parents, teachers, and peers. Journal of Educational Psychology, 90(2), 202-209.

Wilhite, S. C. (1990). Self-efficacy, locus of control, self-assessment of memory ability, and study activities as predictors of college course achievement. Journal of Educational Psychology, 82(4), $696-700$.

Wolters, C. A., Yu, S. L., \& Pintrich, P. R. (1996). The relation between goal orientation and students' motivational beliefs and self-regulated learning. Learning and Individual Differences, 8(3), 211-238.

Wood, R. E., \& Locke, E. A. (1987). The relation of selfefficacy and grade goals to academic performance. Educational and Psychological Measurement, 47(4), 1013-1024.

Yates, L. (2007). The relationship of aptitude, course grades, and program length, to performance on a standards based test (NCLEX-RN). Dissertation Abstracts International, 68(6), B. (UMI No. 3268670)

Yeung, A. S., \& McInerney, D. M. (2000). Facilitating conditions for school motivation. Paper presented at the 13th Annual International Congress for School Effectiveness and Improvement, Hong Kong, China.

Young, J. W. (1993). Grade adjustment methods. Review of Educational Research, 63(2), 151-165.

Young, J. W. (1995). A comparison of two adjustment methods for improving the prediction of law school grades. Educational and Psychological Measurement, 55(4), 558-571. 
Zimmerman, B. J. (1989). A social cognitive view of selfregulated academic learning. Journal of Educational Psychology, 81(3), 329-339. 
APPENDICES 
Appendix A - Cover Letter to Survey Instrument 


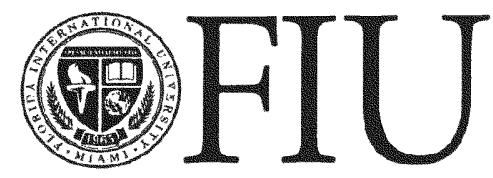

FLORIDA INTERNATIONAL UNIVERSITY

Miami's public research university

Cognitive and Noncognitive Variables that Predict Florida Community College Radiography Program Graduates' Success on the Registry

You are being asked to participate in a research study. As part of this study you will complete the attached questionnaire which is designed to measure your self-efficacy and the level of support received while in the radiography program. Self-efficacy reflects an optimistic self-belief that one can perform difficult tasks and facilitates goal setting and persistence despite barriers. For this study, support refers to that received from your radiography instructor. Your responses to the questionnaire will be compared with your results on the ARRT exam.

Additionally, you will provide the researcher with a copy of your radiography program final grades at the end of the program (reimbursed if transcript sent and college fee incurred) and first-attempt results on the American Registry of Radiologic Technologists (ARRT) exam.

There are no risks to you as a participant of this study. Although there may be no direct benefits to you as an individual, the study may identify new ways to predict success on the ARRT exam. The researcher will maintain the highest level of confidentiality. The information gathered for this study will be used for the purpose of this study. The research results will be presented in a group format. Neither individuals nor community colleges will be identified. Participation in this study will have no effect on your status in the radiography program.

Completing the questionnaire will take no more than 15 minutes. The Agreement to participate in the study and questionnaire will be collected as soon as you are finished. Please feel free to contact me at 954-201-2060, Broward Community College, North Campus, Bldg. 41 Room 109, or Dr. Kingsley Banya at 305-948-1921, Florida International University, College of Education, University Park, Room ZEB 357B. If you have any questions regarding being a human subject, you may contact Dr. Patricia Price, the Chairperson of Florida International University's Institutional Research Board at 305-348- 2618. Sincerely, Gregory J. Ferenchak Principal Investigator 
Appendix B - Survey Instrument 


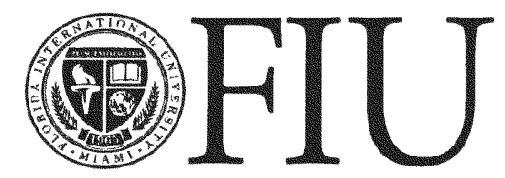

FLORIDA INTERNATIONAL UNIVERSITY

Miami's public research university

Cognitive and Noncognitive Variables that Predict Florida Community College Radiography Program Graduates' Success on the Registry

I, Agreement to Participate in the study participate in the dissertation study of Gregory J. Ferenchak, M.S., R.T.(R) (QM). In so doing I agree to the following as part of this study;

1. Complete the attached Noncognitive questionnaire

2. Supply a copy of my radiography program final grades or transcripts at the end of the program to the researcher (reimbursed if college charge)

3. Supply a copy of my first-attempt results on the American Registry of Radiologic Technologists (ARRT) exam to the researcher.

I am aware that my ARRT exam results (pass or fail) will be used in conjunction with my college transcripts and the Noncognitive questionnaire that I will complete. I further acknowledge that my name or that of my college will not be used in the study.

Student signature:

Date:

This following information will be used to contact you at the end of the program so that your final grades and ARRT results could be matched to your responses to this questionnaire.

Mailing address:

Street Apt .

City state Zip code

Email address:

Telephone number:

Continue on the other side 
Noncognitive Questionnaire

Respond to the 14 statements below based on your present feelings. Please indicate the extent to which you agree or disagree with each of the following items by circling the appropriate response in the box to indicate your answer.

$S A=$ strongly agree, $A=$ agree, $D=$ disagree, $S D=$ strongly disagree

\begin{tabular}{|c|c|c|c|c|}
\hline $\begin{array}{l}\text { 1. I feel comfortable going to my } \\
\text { instructor when I do not understand } \\
\text { what I am supposed to be learning. }\end{array}$ & $S A$ & $\mathbb{A}$ & $D$ & $5 D$ \\
\hline $\begin{array}{l}\text { 2. I can pass the ARRT Exam on the } \\
\text { first try. }\end{array}$ & SA & $\mathbb{A}$ & $D$ & $S D$ \\
\hline $\begin{array}{l}\text { 3. My instructor does not seem to want } \\
\text { to offer advice to me about my } \\
\text { problem. }\end{array}$ & SA & $\mathbb{A}$ & $D$ & $S D$ \\
\hline $\begin{array}{l}\text { 4. I tend to get frustrated and quit if } \\
\text { I cannot solve a riddle. }\end{array}$ & $S A$ & A & $D$ & SD \\
\hline 5. I usually do not complete my goals. & SA & A. & $D$ & $S D$ \\
\hline $\begin{array}{l}\text { 6. My instructor makes it clear what is } \\
\text { expected of me in the program. }\end{array}$ & SA & $\mathrm{A}$ & $D$ & SD \\
\hline $\begin{array}{l}\text { 7. My instructor always seems too busy } \\
\text { to help me. }\end{array}$ & SA & $\mathbb{A}$ & $D$ & $\mathrm{SD}$ \\
\hline $\begin{array}{l}\text { 8. When I believe strongly in } \\
\text { something, I act on it. }\end{array}$ & SA & $\mathbb{A}$ & $D$ & $S D$ \\
\hline $\begin{array}{l}\text { 9. I can always manage to solve } \\
\text { difficult problems if I try hard } \\
\text { enough. }\end{array}$ & $S A$ & A & $D$ & SD \\
\hline $\begin{array}{l}\text { 10. My instructor seems available when I } \\
\text { need questions answered. }\end{array}$ & $\mathrm{SA}$ & A & $D$ & $\mathrm{SD}$ \\
\hline $\begin{array}{l}\text { 11. It is easy for me to stick to } \\
\text { something and accomplish my goal. }\end{array}$ & SA & $\mathbb{A}$ & $D$ & SD \\
\hline $\begin{array}{l}\text { 12. My instructor does not seem to } \\
\text { acknowledge my achievements. }\end{array}$ & $S A$ & A & $D$ & $S D$ \\
\hline $\begin{array}{l}\text { 13. I will have to study more after } \\
\text { graduation if I want to pass the } \\
\text { ARRT Exam on my first try. }\end{array}$ & SA & $\mathbb{A}$ & $D$ & SD \\
\hline $\begin{array}{l}\text { 14. My instructor gives me frequent } \\
\text { feedback on how I am doing in the }\end{array}$ & SA & $\mathbb{A}$ & $D$ & SD \\
\hline
\end{tabular}


The following information will be used for general reporting purposes only.

15. What is your gender? (Circle one) 1) Male 2) Female

16. Enter the 4-digit year you were born (for example 1978).

17. What is your race/ ethnic background? (Circle one)

1) American Indian or Alaskan Native

2) Asian or Pacific Islander

3) Black

4) Hispanic

5) White (not of Hispanic origin)

6) Other

Thank you very much for participating in this survey.

This section to be completed by researcher

Study ID \# 
Appendix C - Key to Questionnaire 
Noncognitive Questionnaire Key

\begin{tabular}{|c|c|c|c|c|c|c|}
\hline \multicolumn{2}{|c|}{$\begin{array}{l}\text { Strongly Agree }=S A, \text { Agree }=A, \\
\text { Disagree }=D, \text { Strongly Disagree }=S D\end{array}$} & CODE & SA & A & D & SD \\
\hline 1. & $\begin{array}{l}\text { I feel comfortable going to my } \\
\text { instructor when I do not understand } \\
\text { what I am supposed to be learning. }\end{array}$ & SS+ & 4 & 3 & 2 & 1 \\
\hline 2. & $\begin{array}{l}\text { I can pass the ARRT Exam on the } \\
\text { first try. }\end{array}$ & SE+ & 4 & 3 & 2 & 1 \\
\hline 3 . & $\begin{array}{l}\text { My instructor does not seem to want to } \\
\text { offer advice to me about my problem. }\end{array}$ & SS- & 1 & 2 & 3 & 4 \\
\hline 4. & $\begin{array}{l}\text { I tend to get frustrated and quit if } \\
\text { I cannot solve a riddle. }\end{array}$ & SE- & 1 & 2 & 3 & 4 \\
\hline 5. & I usually do not complete my goals. & SE- & 1 & 2 & 3 & 4 \\
\hline 6. & $\begin{array}{l}\text { My instructor makes it clear what is } \\
\text { expected of me in the program. }\end{array}$ & SS+ & 4 & 3 & 2 & 1 \\
\hline 7. & $\begin{array}{l}\text { My instructor always seems too busy to } \\
\text { help me. }\end{array}$ & ss- & 1 & 2 & 3 & 4 \\
\hline 8. & $\begin{array}{l}\text { When I believe strongly in something, } \\
\text { I act on it. }\end{array}$ & SE+ & 4 & 3 & 2 & 1 \\
\hline 9. & $\begin{array}{l}\text { I can always manage to solve difficult } \\
\text { problems if I try hard enough. }\end{array}$ & $\mathrm{SE}+$ & 4 & 3 & 2 & 1 \\
\hline 10. & $\begin{array}{l}\text { My instructor seems available when I } \\
\text { need questions answered. }\end{array}$ & SS+ & 4 & 3 & 2 & 1 \\
\hline 11. & $\begin{array}{l}\text { It is easy for me to stick to } \\
\text { something and accomplish my goal. }\end{array}$ & $\mathbf{S E}+$ & 4 & 3 & 2 & 1 \\
\hline 12. & $\begin{array}{l}\text { My instructor does not seem to } \\
\text { acknowledge my achievements. }\end{array}$ & ss- & 1 & 2 & 3 & 4 \\
\hline 13. & $\begin{array}{l}\text { I will have to study more after } \\
\text { graduation if I want to pass the ARRT } \\
\text { Exam on my first try. }\end{array}$ & SE- & 1 & 2 & 3 & 4 \\
\hline 14. & $\begin{array}{l}\text { My instructor gives me frequent } \\
\text { feedback on how I am doing in the } \\
\text { program. }\end{array}$ & SS+ & 4 & 3 & 2 & 1 \\
\hline
\end{tabular}

Score for self-efficacy (SE)

Items: $2+4+5+8+9+11+13+2+\square=$

Score for social support (SS)

Items: $\begin{array}{r}1+3+6+7+10+12+14 \\ +\end{array}$ 
Appendix D - Data Form for Course Grades and ARRT Results with cover letter 


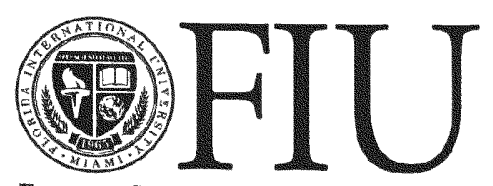

FLORIDA INTERNATIONAL UNIVERSITY

Miami's public research university

Cognitive and Noncognitive Variables that Predict Florida Community College Radiography Program Graduates' Success on the Dear Study Participant: Registry

Thank you for participating in my research study. Initially you completed a questionnaire which was designed to measure your self-efficacy and the level of support received while in the radiography program. At that time you agreed to submit a copy of your radiography program final grades and your first-attempt results on the American Registry of Radiologic Technologists (ARRT) exam to me. Please complete the form on the back of this letter to complete your participation in the study. If you have not taken the ARRT exam yet, please wait until obtaining the results of your first-attempt on the exam before submitting the form.

As I previously indicated to you, there are no risks to you as a participant of this study. Although there may be no direct benefits to you as an individual, the study may identify new ways to predict success on the ARRT exam. I will maintain the highest level of confidentiality. The information gathered for this study will be used for the purpose of this study. The research results will be presented in a group format. Neither individuals nor community colleges will be identified. Participation in this study will have no effect on your status in the radiography program.

Completing the attached form will take no more than 15 minutes. once completed, please return the form to me in the enclosed envelope. If you have any questions, please feel free to contact me at 954-201-2060, Broward Community College, North Campus, Bldg. 41 Room 109, or Dr. Kingsley Banya at 305-948-1921, Florida International University, College of Education, University Park, Room $\mathrm{ZEB}$ 357B. If you have any questions regarding being a human subject, you may contact Dr. Patricia Price, the Chairperson of Florida International University's Institutional Research Board at 305-348-2618. I want to thank you for participating in my study.

Sincerely,

Gregory J. Ferenchak

Principal Investigator 
Participant Case \#:

1. Course Grades (all course required for the degree in radiography)

\begin{tabular}{|c|c|c|}
\hline Course & Credits & $\begin{array}{c}\text { Final } \\
\text { Grade }\end{array}$ \\
\hline ENC 1101 & 3 & \\
\hline SPC 1026 & 3 & \\
\hline PPE 1005 & 3 & \\
\hline PHI 2604 & 3 & \\
\hline BSC 1085 & 3 & \\
\hline BSC 1085L & 1 & \\
\hline BSC 2085 & 3 & \\
\hline BSC 2085L & 1 & \\
\hline RTE 1000 & 2 & \\
\hline RTE 1002 & 1 & \\
\hline RTE 1418 & 3 & \\
\hline RTE 1503 & 3 & \\
\hline RTE 1503L & 1 & \\
\hline RTE 1804 & 5 & \\
\hline RTE 1513 & 3 & \\
\hline RTE 1513L & 1 & \\
\hline RTE 1613 & 2 & \\
\hline RTE 1814 & 5 & \\
\hline RTE 1824 & 5 & \\
\hline RTE 2457 & 2 & \\
\hline RTE 2523 & 2 & \\
\hline RTE 2782 & 2 & \\
\hline RTE 2834 & 5 & \\
\hline RTE 2385 & 2 & \\
\hline RTE 2473L & 1 & \\
\hline RTE 2844 & 8 & \\
\hline RTE 2854 & 4 & \\
\hline & 77 & \\
\hline
\end{tabular}

2. ARRT first-attempt results (circle one): passed failed

Do not complete the portion below the line

$1^{\text {st }}$ GPA:

$2^{\text {nd }}$ GPA: 
Appendix E - Radiography Curriculum Courses and Matching ARRT Sections 
Table E1

Radiography Curriculum Courses and Matching ARRT Sections

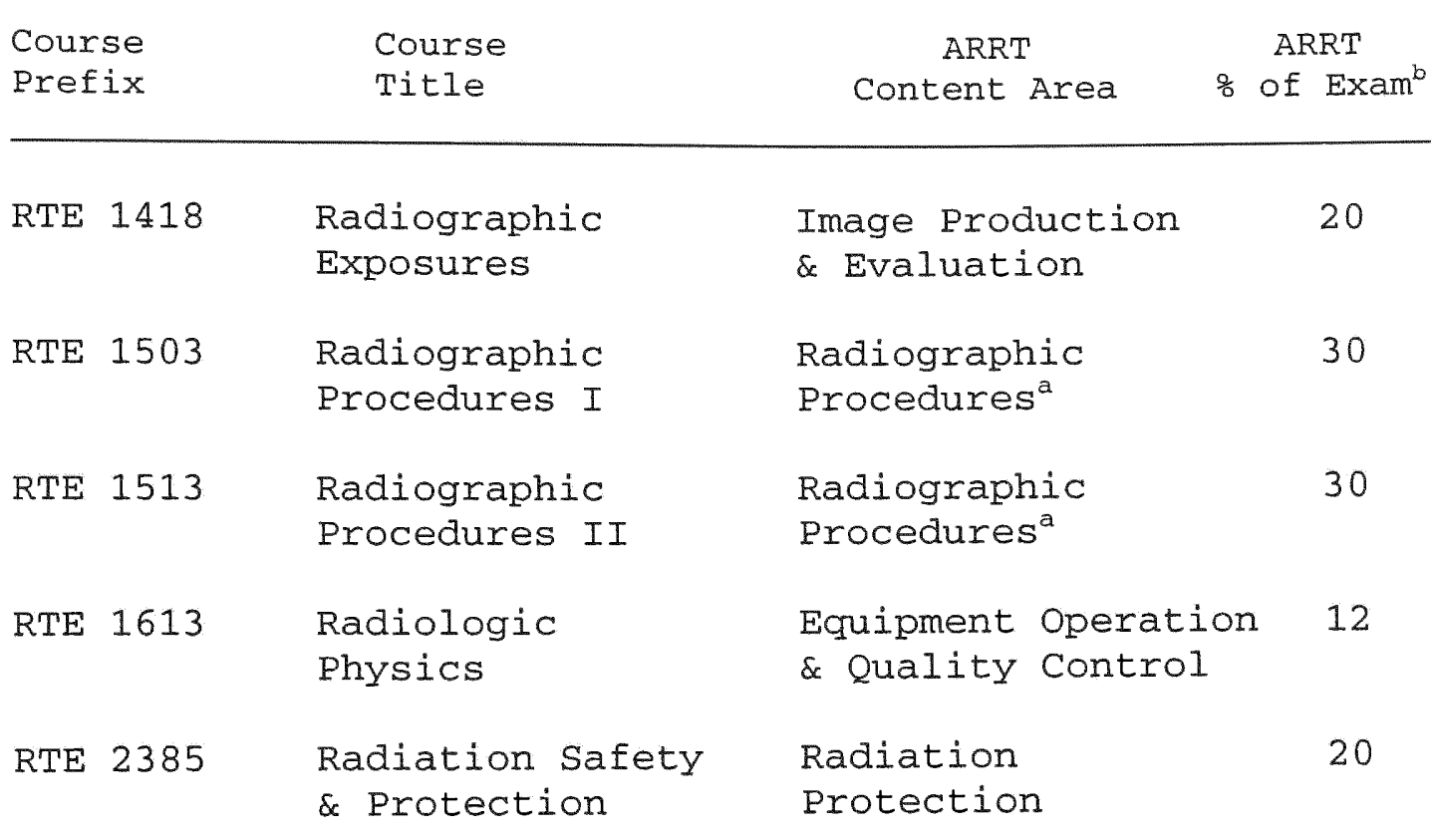

Note. ${ }^{a}$ Same section. ${ }^{b}$ Only relevant sections of ARRT Exam displayed. 


\section{VITA}

\section{GREGORY J . FERENCHAK}

Born, Youngstown, $\mathrm{OH}$

$1973-1975$

$1975-1977$

1977

$1977-1978$

$1977-1979$

$1979-1980$

$1980-1981$

$1981-1982$

$1982-1983$
Youngstown State University

Youngstown, OH

Certificate, Radiologic Technology St. Elizabeth Hospital

School f Radiologic Technology

Youngstown, $\mathrm{OH}$

Certified in Radiography The American Registry of Radiologic Technologists

st. Paul, MN

Youngstown State University

Youngstown, $\mathrm{OH}$

Radiologic Technologist

St. Elizabeth Hospital

Youngstown, $\mathrm{OH}$

Bachelor of Science, Biology

Greensboro College

Greensboro, NC

Certificate, Advanced Radiologic Technology

Duke University

Durham, NC

Chief Radiologic Technologist and Clinical Instructor

Community Memorial Hospital

South Hill, VA

Faculty

Radiologic Technology Program

Vance-Granville Community College Henderson, NC 
Faculty and Program Director Radiologic Technology Tidewater Community College Virginia Beach, VA

Master of Science, Adult Education old Dominion University Norfolk, VA

Department Chair School of Allied Health Technologies Miami Dade College- Medical Center Campus

Miami, FL

Certified in Quality Management The American Registry of Radiologic Technologists St. Paul, MN

2006-Present

Dean, Health Sciences Broward College- North Campus Fort Lauderdale, FL 